\title{
Effect of Obstructive Sleep Apnea Hypopnea Syndrome on Lipid Profile: A Meta-Regression Analysis
}

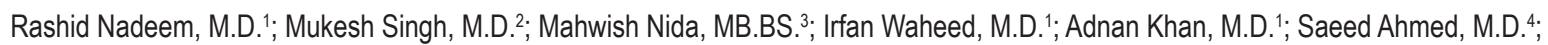
Jawed Naseem, M.Sc. ${ }^{5}$; Daniel Champeau, M.S. ${ }^{1}$

${ }^{1}$ Rosalind Franklin University of Medicine and Science, Chicago Medical School, North Chicago,IL; ${ }^{2}$ Department of Cardiology, James A Lovell Federal Health Care Center, North Chicago, IL; ${ }^{3}$ Rematul lil Alameen Institute of Cardiology, Lahore, Pakistan;

${ }^{4}$ New York University, New York, NY; ${ }^{5}$ University of Karachi, Karachi, Pakistan

Background: Obstructive sleep apnea (OSA) is associated with obesity, metabolic syndrome, and dyslipidemia, which may be related to decrease androgen levels found in OSA patients. Dyslipidemia may contribute to atherosclerosis leading to increasing risk of heart disease.

Methods: Systematic review was conducted using PubMed and Cochrane library by utilizing different combinations of key words; sleep apnea, obstructive sleep apnea, serum lipids, dyslipidemia, cholesterol, total cholesterol, low density lipoprotein (LDL), high density lipoprotein (HDL), and triglyceride (TG). Inclusion criteria were: English articles, and studies with adult population in 2 groups of patients (patients with OSA and without OSA). A total 96 studies were reviewed for inclusion, with 25 studies pooled for analysis.

Results: Sixty-four studies were pooled for analysis; since some studies have more than one dataset, there were 107 datasets with 18,116 patients pooled for meta-analysis. All studies measured serum lipids. Total cholesterol pooled standardized difference in means was $0.267(p=0.001)$. LDL cholesterol pooled standardized difference in means was $0.296(p=0.001)$. HDL cholesterol pooled standardized difference in means was $-0.433(p=0.001)$. Triglyceride pooled standardized difference in means was 0.603 $(p=0.001)$. Meta-regression for age, BMI, and AHI showed that age has significant effect for TC, LDL, and HDL. BMI had significant effect for LDL and HDL, while AHI had significant effect for LDL and TG.

Conclusion: Patients with OSA appear to have increased dyslipidemia (high total cholesterol, LDL, TG, and low HDL). Keywords: obstructive sleep apnea, dyslipidemia, cholesterol, atherosclerosis, sleep disordered breathing

Citation: Nadeem R, Singh M, Nida M, Waheed I, Khan A, Ahmed S, Naseem J, Champeau D. Effect of obstructive sleep apnea hypopnea syndrome on lipid profile: a metaregression analysis. J Clin Sleep Med 2014;10(5):475-489.

$\mathrm{O}$ bstructive sleep apnea (OSA) is a common disorder affecting about $4 \%$ of middle-aged males and $2 \%$ of middle-aged women in the developed world and is a significant source of morbidity and mortality. ${ }^{1,2}$ OSA is characterized by recurrent episodes of upper airway collapses during sleep. These recurrent episodes of upper airway collapse usually are accompanied by oxyhemoglobin desaturation and terminated by brief arousals which result in marked sleep fragmentation and chronic excessive daytime sleepiness (EDS). ${ }^{1,2}$

OSA has been increasingly linked to cardiovascular and cerebrovascular disease, and many studies have shown that OSA is associated with increased cardiovascular and cerebrovascular morbidity.-9 ${ }^{3-9}$ OSA is associated with obesity and metabolic syndrome. ${ }^{10}$ Multiple studies addressing this interesting and complex issue are available where lipid profile was measured in subjects with OSA. ${ }^{11-35}$ We performed metaanalysis (MA) and meta-regression (MR) to specifically detect if OSA adversely affects degree of dyslipidemia; elevation of total cholesterol (TC), low density lipoprotein cholesterol (LDL), triglyceride (TG), and reduces level of high density lipoprotein cholesterol (HDL).

\section{BRIEF SUMMARY}

Current Knowledge/Study Rationale: Dyslipidemia (increase in total cholesterol, LDL, and triglycerides, and decrease in HDL) and obstructive sleep apnea (OSA) are risk factors for cardiovascular and cerebrovascular disorders. This meta-regression analysis estimates the adverse effect of OSA on dyslipidemia as many studies have measured dyslipidemia in subjects with OSA.

Study Impact: Study suggests dyslipidemia may be the mechanism of atherosclerosis in subjects with OSA. It also suggests OSA as potential target for treatment to improve dyslipidemia for prevention and treatment for cardiovascular and cerebrovascular disease.

\section{METHODS}

\section{Data Source and Study Selection}

Studies for review were found searching the PubMed, Cochrane, and EMBASE databases from January 01, 1968, to November 30th, 2013. Unpublished data from scientific meetings were not searched, since most abstract do not provide detail raw data needed for meta-analysis. Searches were 


\section{Figure 1-Flow diagram for search and inclusion and exclusion of studies}
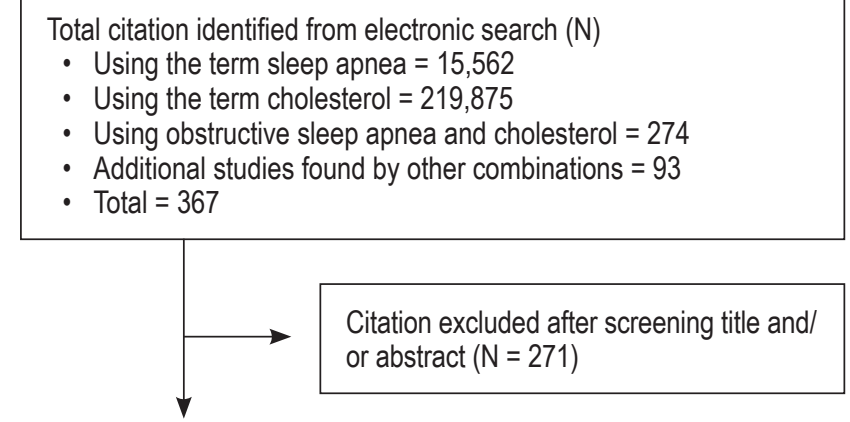

Articles retrieved for detailed evaluation (full text, if available) $(\mathrm{N}=96)$

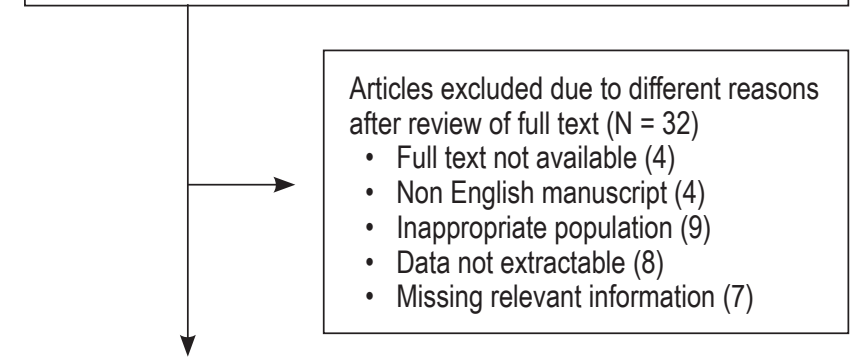

Articles included in the meta-analysis $(\mathrm{N}=64)$

conducted using the keywords; sleep apnea, obstructive sleep apnea, serum lipids, dyslipidemia, cholesterol, total cholesterol, low density lipoprotein, high density lipoprotein, and triglyceride. Each target outcome was also searched in its abbreviated forms (Chol T, HDL, LDL, and TG) to ensure that no relevant source was left out. Additionally, each target and its abbreviated forms were searched in combination with obstructive sleep apnea. Multiple authors individually searched for and scored manuscripts for inclusion. If manuscripts scored differently by 2 authors then it was reviewed by third author to finalize its inclusion.

\section{Studies and Endpoint Definitions}

Lipid profile includes total cholesterol (TC), low density lipoprotein cholesterol (LDL), high density lipoprotein cholesterol (HDL), and triglyceride (TG). Inclusion criteria defined for subsequent study selection were as follows: (1) the study must be in English, (2) studies with adult population only, (3) full-text manuscripts had to be available, (4) the study must have reported values for at least one of the outcome of interest, (5) the study must have included $\geq 2$ separate groups with one being a group consisting of individuals with obstructive sleep apnea and the other consisting of individuals without obstructive sleep apnea, (6) OSA was defined as AHI $\geq 5 / \mathrm{h}$, (7) the study must have reported values in mean and standard deviation or median with range, and (8) patient number for all groups must have been reported.

\section{Data Extraction and Statistical Analysis}

Studies identified for inclusion then underwent data extraction. Data was extracted at a study level by a single author and then reviewed by a second author to ensure no errors were made. Levels of serum lipids were extracted from studies as mean with standard deviation. For studies with data reported in median and range, mean and standard deviation were calculated utilizing methods outlined by Hozo et al. ${ }^{36}$

For studies in which OSA patients were compared with more than one group of control patients (e.g., obese and lean control), each set of data in the study was included in the meta-analysis as a separate data set. For example, Barcelo et al. compared lipid profiles of obese OSA patients and non-obese OSA to healthy controls. ${ }^{11}$ We used standardized differences in means method for analyzing extracted data from studies.

Study selection, data extraction, and statistical analysis were all done in accordance to previously published methodology for meta-analyses. All statistical analysis was done using Comprehensive Meta-Analysis Version 2.

Heterogeneity was assessed by calculating the Cochrane Q statistic. Additionally $\mathrm{I}^{2}$ statistics was also calculated to assess heterogeneity. An $\mathrm{I}^{2}$ of $25 \%$ to $49 \%$ was considered to represent a low level of heterogeneity, $50 \%$ to $60 \%$ a moderate level, and $60 \%$ to $100 \%$ a high level. Standardized differences in mean were calculated using a random effects model for all outcomes with $>60 \%$ heterogeneity $\left(\mathrm{I}^{2}>60\right)$ and fixed effect model for $\mathrm{I}^{2}<60$. Measurement unit of lipid profile was $\mathrm{mmol} / \mathrm{L}$. If any of these values were in $\mathrm{mg} / \mathrm{dL}$ they were converted into $\mathrm{mmol} / \mathrm{L}$ by dividing them by their molar weight. Publication bias analysis was done using four different methods to provide robust results. The methods included funnel plot analysis, Eggers reg intercept, Duval and Tweedie trim and fill, and Kendall tau with and without continuity correction.

\section{RESULTS}

The literature was ranked according to the hierarchy of evidence of Sackett et al. ${ }^{37}$ A total of 96 studies were reviewed for inclusion. Sixty-four studies (with 107 datasets) met inclusion criteria and pooled for meta-analysis including total subjects 18,116 (controls [ $\mathrm{N}=10,145]$ and OSA subjects $[\mathrm{N}=7,971]$ ) for analysis (Figure 1).

\section{Total Cholesterol}

A total of 63 studies with 107 datasets including 18,111 subjects were pooled for TC. Standardized differences in means ranged from -2.05 to 5.0 ; pooled mean difference was calculated to be 0.267 (lower limit [LL] 0.146 to upper limit [UL] 0.389 , $\mathrm{p}$ value $=0.001$; see appendix following references, Figure A1).

\section{LDL Cholesterol}

For LDL, 50 studies with 82 datasets including 13,894 subjects were pooled. Standardized mean difference in LDL ranged from -1.679 to 3.243 , pooled mean difference was calculated to be 0.296 (LL 0.156 to UL 0.436, p $=0.001$; Figure A2) 
Table 1-Meta Regression statistics for Lipids (TC, LDL, HDL, TG) for Age, BMI, and AHI

\begin{tabular}{lccc} 
& \multicolumn{3}{c}{ Age } \\
\cline { 2 - 4 } TC & slope & intercept & \multicolumn{1}{c}{$\mathbf{p}$} \\
LDL & -0.02 & 1.37 & 0.001 \\
HDL & 0.004 & 0.011 & 0.04 \\
TG & -0.01 & 0.39 & 0.001 \\
& -0.002 & 0.55 & 0.34
\end{tabular}

\begin{tabular}{ccc}
\multicolumn{3}{c}{ BMI } \\
\hline slope & intercept & $\mathbf{p}$ \\
-0.0052 & 0.23 & 0.12 \\
0.02 & 0.85 & 0.001 \\
0.02 & -1.18 & 0.001 \\
-0.002 & 0.51 & 0.51
\end{tabular}

\begin{tabular}{ccc}
\multicolumn{3}{c}{ AHI } \\
\hline slope & intercept & $\mathbf{p}$ \\
-0.0005 & 0.04 & 0.65 \\
0.0006 & 0.22 & 0.67 \\
-0.005 & -0.24 & 0.001 \\
0.007 & 0.18 & 0.001
\end{tabular}

Figure 2-Meta-regression plots for age on TC, LDL, HDL, and TG

TC

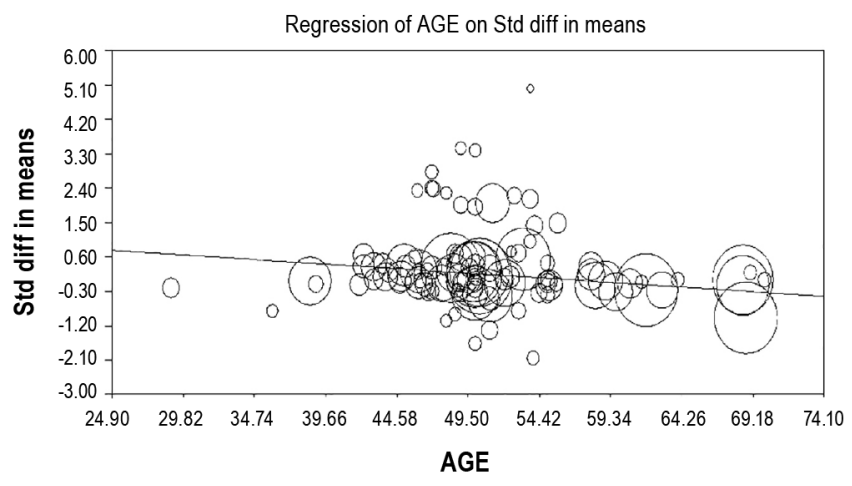

HDL

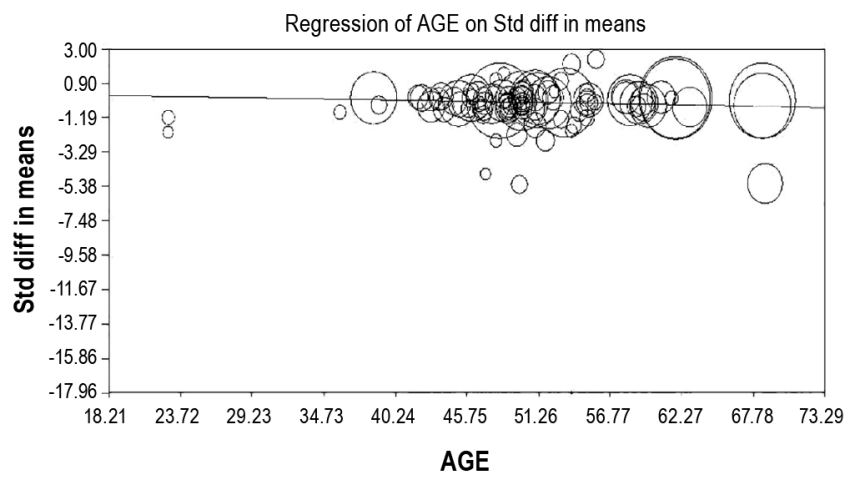

LDL

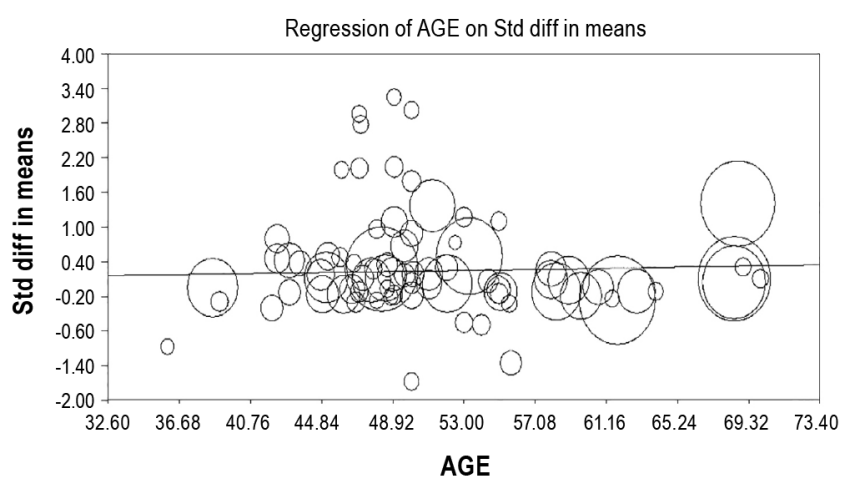

TG

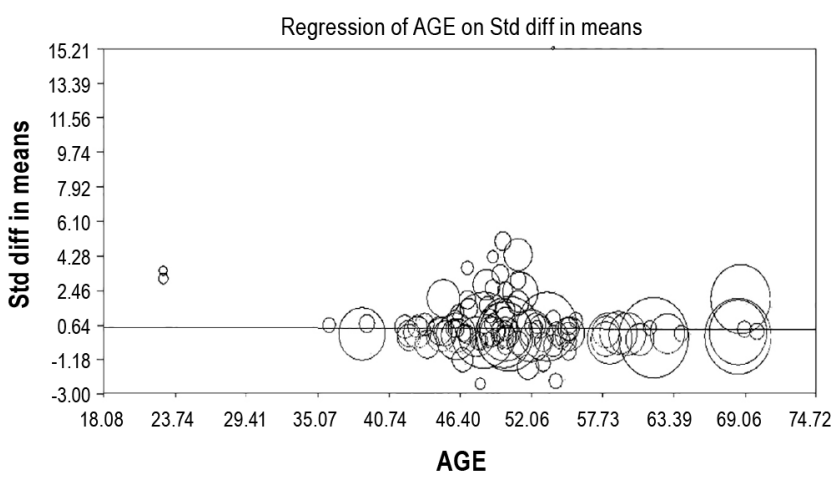

\section{HDL Cholesterol}

For HDL, 64 studies with 107 datasets including 18,116 subjects were pooled. Standardized mean difference ranged from -17.96 to 2.364 . The pooled mean difference was calculated to be -0.433 (LL -0.604 to UL $-0.262, \mathrm{p}<0.001$; Figure A3).

\section{Triglyceride}

For TG, 62 studies with 104 datasets including 17,831 subjects were pooled and analyzed. Standardized mean difference ranged from -2.476 to 15.206 , pooled mean difference was calculated to be 0.603 (LL 0.431 to UL $0.775, p<0.001$; Figure A4).

\section{Meta-Regression to evaluate the effect of Age, BMI, and $\mathrm{AHI}$ on Lipid Levels}

Data was also analyzed by meta-regression for effect of age, BMI, and AHI on all 4 variables of interest. Results of this analysis are given in Table 1. Age had significant effect for TC, LDL, and HDL. BMI had significant effect for LDL and HDL, while AHI had significant effect for HDL and TG (Figures 2-4). Only AHI had significant effect for TG.

\section{Publication Bias Analysis}

Publication bias analysis was done using four different methods to provide robust results. The methods included funnel plot analysis (Figure 5), Eggers reg intercept, Duval and Tweedie trim and fill, and Kendall tau with and without continuity correction. Overall, there was no significant publication bias in combined analysis. We also performed this analysis for individual lipid components and this analysis showed that there is low likelihood of publication bias for TC, TG, and LDL-c. HDL-c analysis showed likelihood of publication bias. We also performed precision plots (Figure 6).

\section{Sensitivity Analysis}

We also performed sensitivity analysis by removing one study at each step that did not change results, and it makes our results more robust (Figures A5-A8). 
Figure 3-Meta-regression plots for BMI on TC, LDL, HDL, and TG

TC

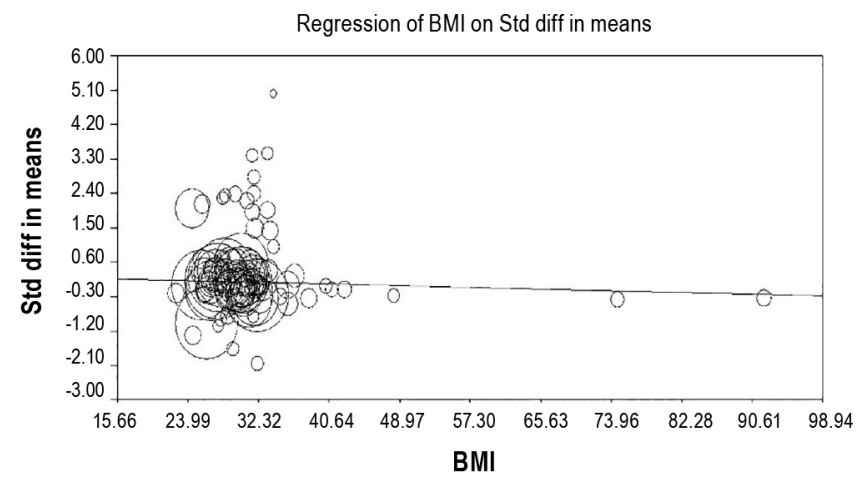

HDL

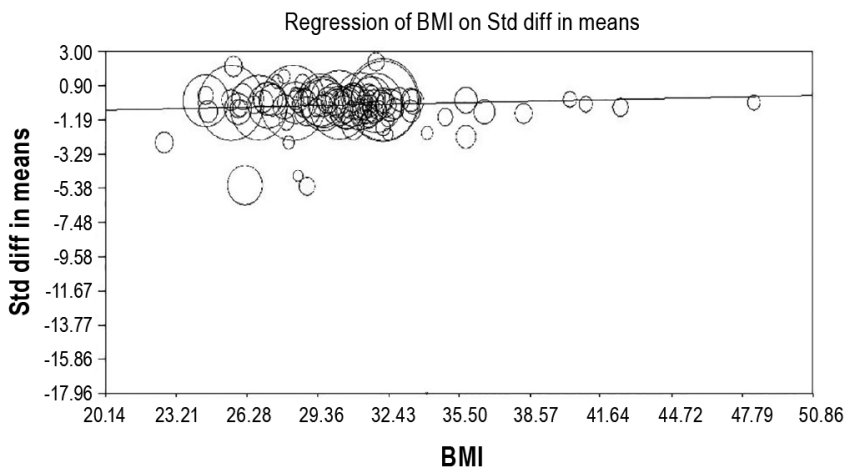

LDL

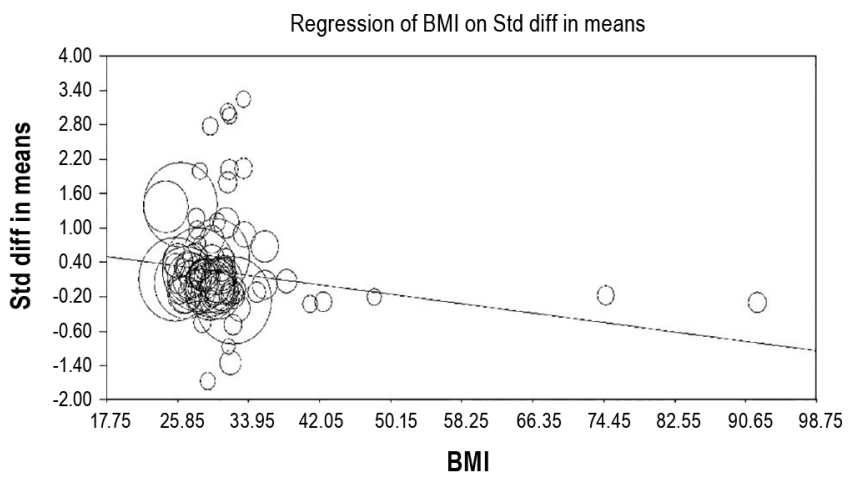

TG

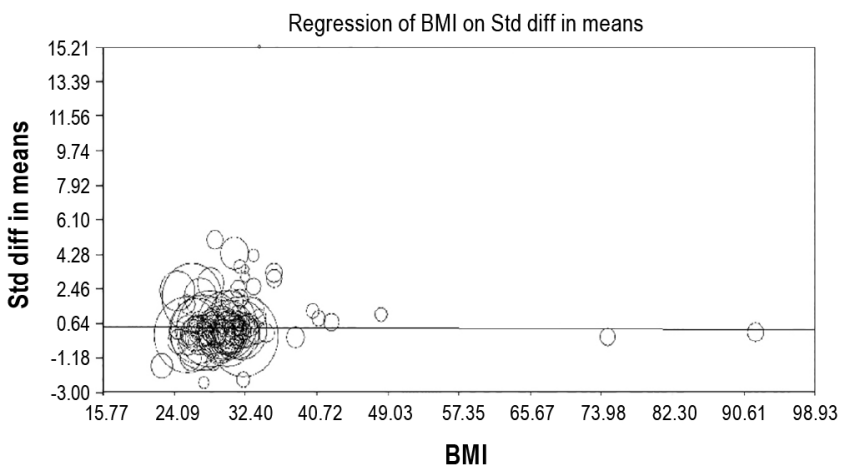

Figure 4-Meta-regression plots for AHI on TC, LDL, HDL, and TG

TC

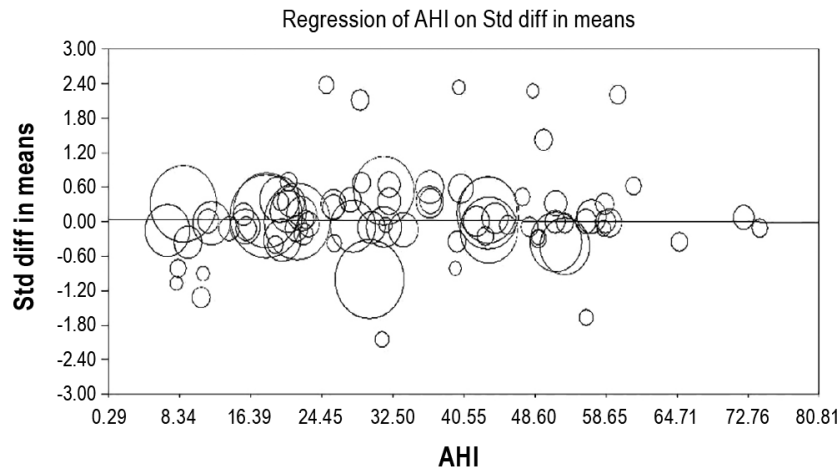

HDL

Regression of AHI on Std diff in means

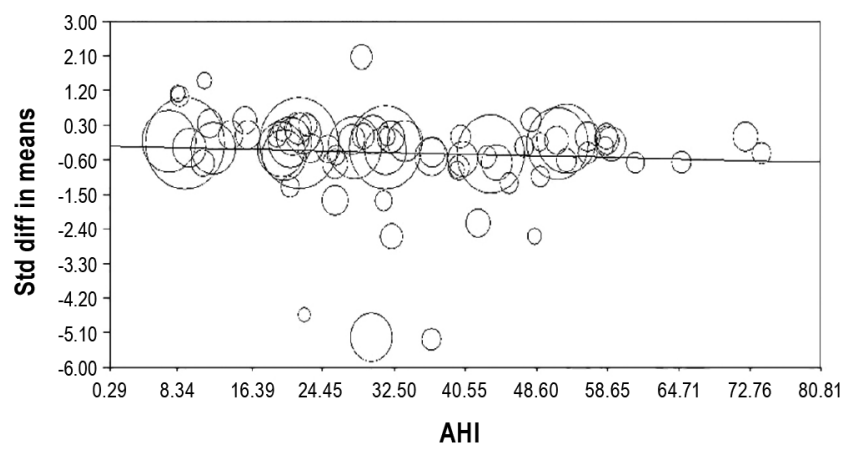

LDL

Regression of AHI on Std diff in means

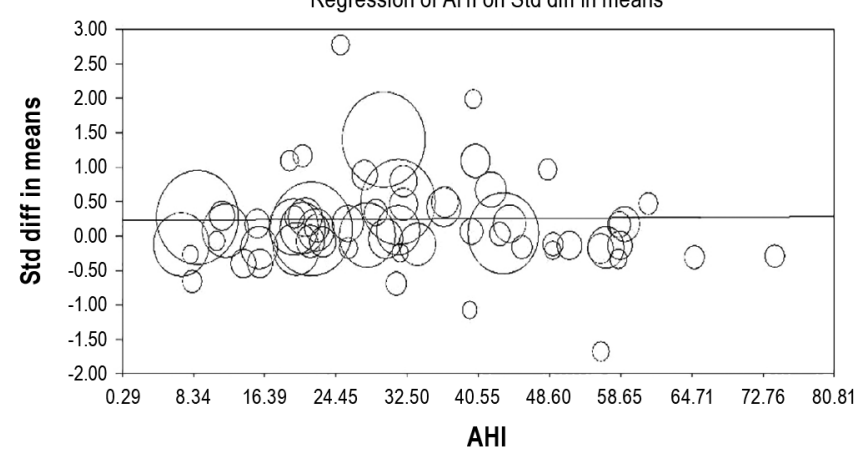

TG

Regression of AHI on Std diff in means

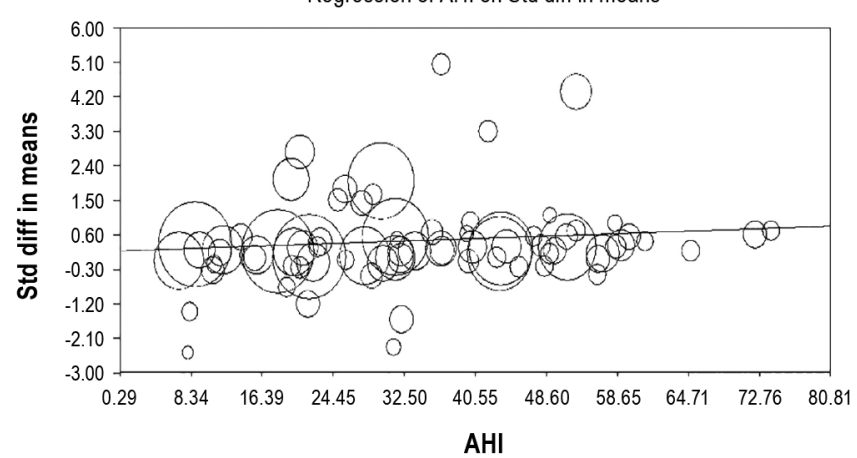


Figure 5-Publication bias estimation, Funnel plots for TC, LDL, HDL, and TG

TC

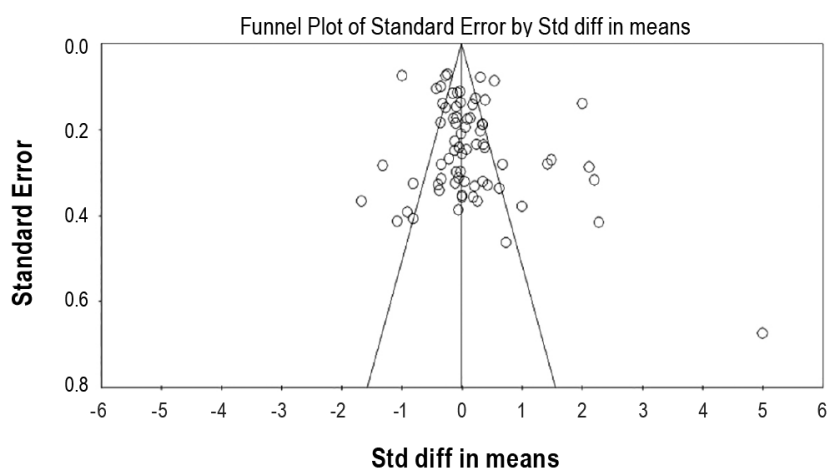

HDL

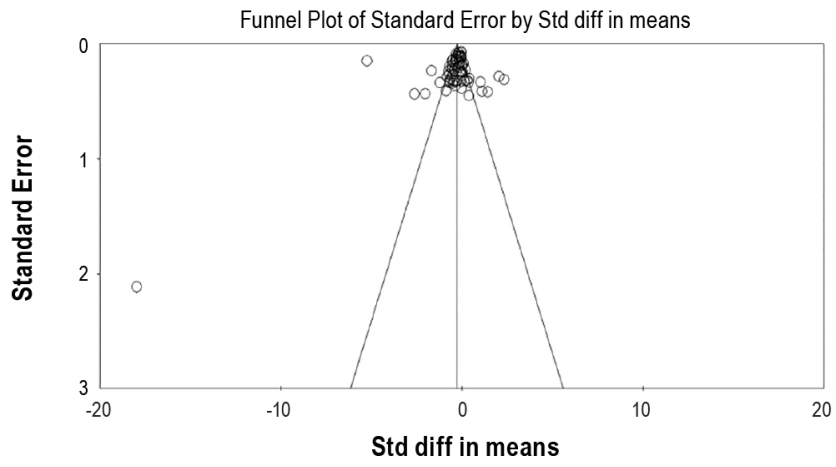

LDL

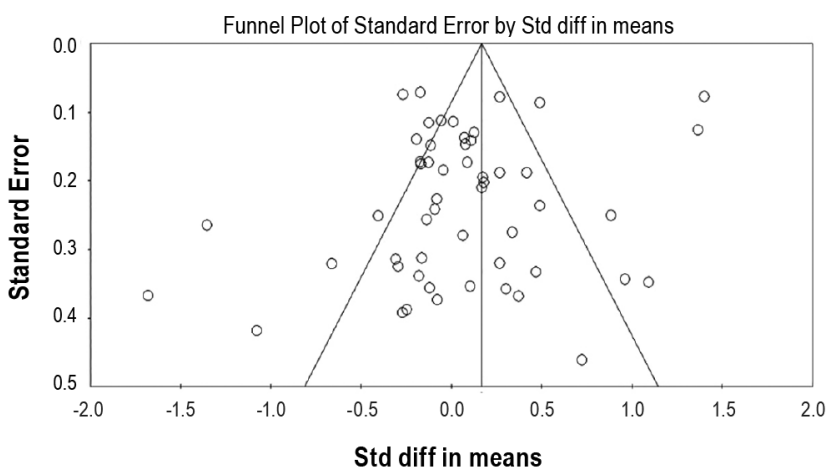

TG

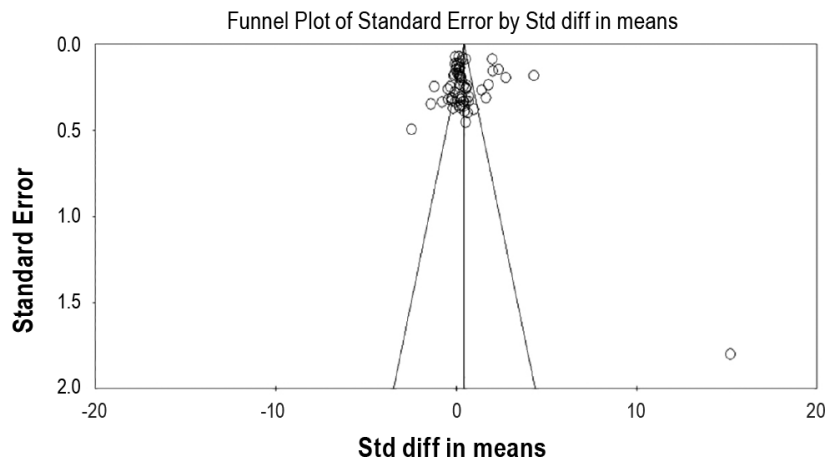

Figure 6-Precision plot analyses

TC

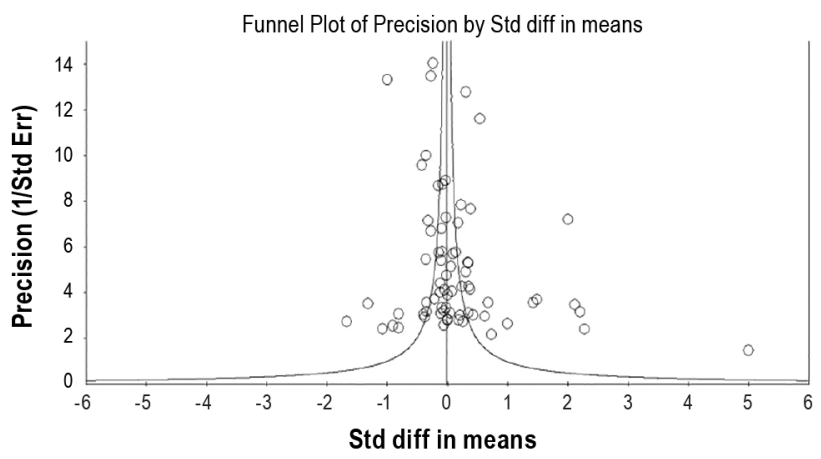

HDL

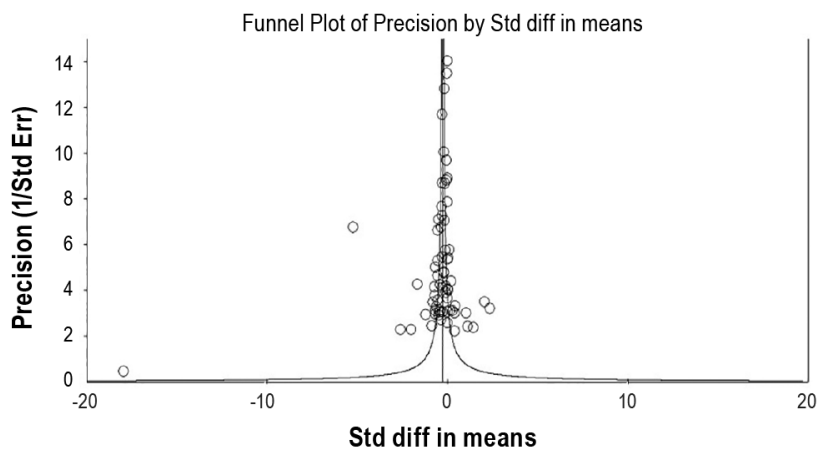

LDL

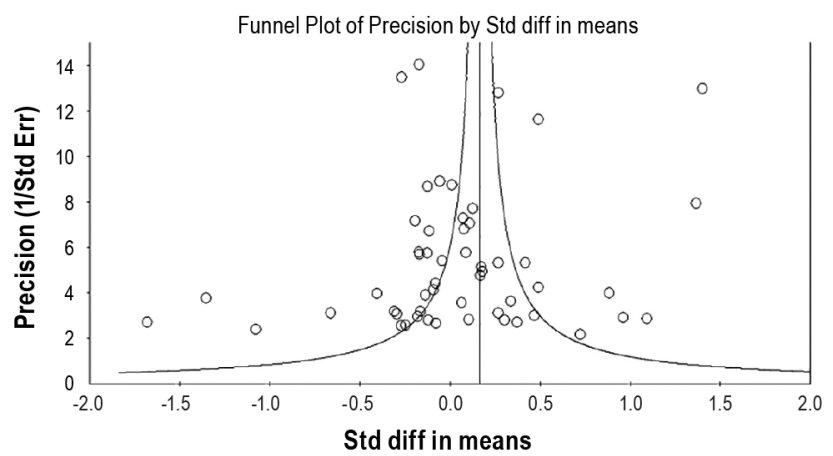

TG

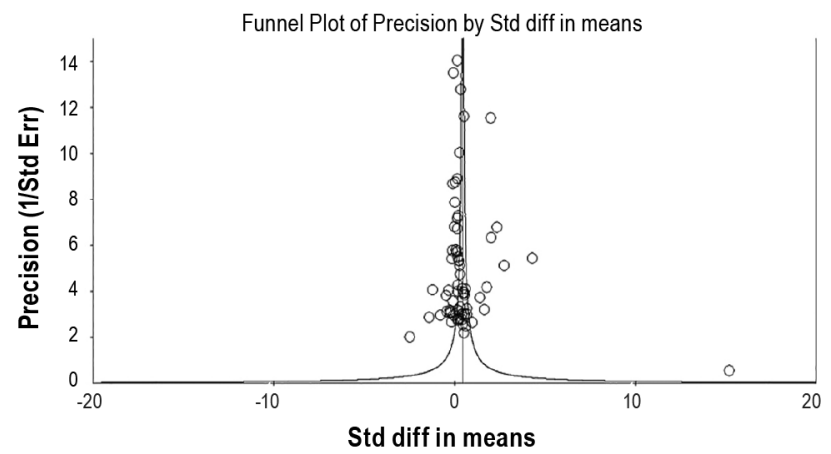




\section{DISCUSSION}

There is strong positive associations between low-density lipoprotein (LDL) particles, which carry cholesterol, and the risk of coronary heart disease (CHD). ${ }^{38,39}$ Randomized trials have demonstrated that lowering LDL cholesterol with medications reduces the risk of cardiac death, nonfatal myocardial infarction (MI), ischemic stroke, and the need for revascularization procedures. ${ }^{40-42}$

Although a clear causal relationship of OSA and dyslipidemia is yet to be demonstrated, there is increasing evidence that chronic intermittent hypoxia, a major component of OSA, is independently associated and possibly the root cause of the dyslipidemia via the generation of stearoyl-coenzyme A desaturase-1 and reactive oxygen species, peroxidation of lipids, and sympathetic system dysfunction. ${ }^{43}$ Intermittent hypoxia associated with sleep apnea promotes oxidative, and immune-inflammatory alterations. ${ }^{44}$ Systemic inflammatory markers are higher in OSA patients than control subjects. ${ }^{45}$ Cytokines, specifically IL-1, may alter LDL metabolism by human vascular endothelial cells and alter endothelial cell cholesterol metabolism. These changes in endothelial cell metabolism provide evidence supporting the critical role of cytokines in atherogenesis. ${ }^{46}$

The present meta-analysis (MA) showed that there is an increase in levels of dyslipidemia in subjects with OSA including total cholesterol, low density lipoprotein, high density lipoprotein, and triglyceride. An obvious majority of studies ${ }^{11-26,31-35}$ showed this effect, while few did not. ${ }^{27,30,31}$ Ozol et al. found less dyslipidemia in patients with moderate OSA than controls, most likely because their controls have high insulin resistance measured by HOMA and higher insulin levels than moderate OSA patients. ${ }^{27}$ Moreover they found a high degree of dyslipidemia in their mild and severe OSA groups, which suggest that confounding factors may have played a role in their subjects' lipid levels (hypertension, obesity, and frequency of metabolic syndrome) in their sample. Another study which did not show significant dyslipidemia in OSA was by Salord et al. Their small sample (OSA, $n=15$ and control $n=12$ ) had unique characteristics: all controls without OSA were significantly obese (BMI 46.9) undergoing bariatric surgery. ${ }^{31}$ Moreover their OSA patients were being treated with CPAP, which may explain the different findings of the study.

These findings highlight the adverse role of OSA as risk factor for cardiovascular diseases. These finding also suggest that increasing dyslipidemia may also be the mechanism of atherosclerosis in patients with OSA. It provides a potential target for treatment of dyslipidemia. Conceivably there is data suggesting that treatment of OSA by CPAP improves dyslipidemia, atherosclerosis and cardiovascular disease. ${ }^{47}$

\section{Meta-regression Analysis for Confounding Variables}

These MR plots show that dyslipidemia (HDL and TG) is correlated by severity of OSA, higher the AHI the higher the dyslipidemia. Gasa et al. ${ }^{19}$ show that level of dyslipidemia correlates well with the severity of OSA; gradual worsening with worst numbers found in severe OSA group. Their regression analysis showed beta of 0.007 for TG. Likewise, Peled et al. found dyslipidemia in their sample as follow; control $<$ mild OSA $<$ severe OSA $<$ moderate OSA ${ }^{30}$. Their Beta coefficient was 0.332 for AHI, which suggests that this relationship is probably confounded by multiple factors including weight, BMI, and comorbid conditions.

These MR plots also showed the modest but significant effect of BMI on dyslipidemia (LDL and HDL). This is in agreement with many other studies. Sharma et al. showed that BMI had an independent association with OSA.

This finding of heightened dyslipidemia in patients with obstructive sleep apnea suggest that treatment of sleep apnea should improve this risk factors for heart disease directly or indirectly by affecting other confounding factors (obesity, hypertension, diabetes mellitus, and metabolic syndrome), as CPAP treatment for sleep apnea has been shown to positively affect management of these confounding variables. ${ }^{48-51}$

Several limitations of this meta-analysis should be emphasized. Available literature is low level evidence. Many of the relevant studies regarding the association between OSA and level of dyslipidemia were cross-sectional in nature, so the temporal relationships between these two factors were unclear. Funnel plots suggest heterogeneity and publication bias (Figure 5). We could not perform the meta-regression for other confounding factors - sleepiness, presence of hypertension, or measures of visceral adipose tissue - since we have data on these variables only in few studies. These factors have been found to be associated with elevated dyslipidemia.

One weakness of our meta-analysis is that all papers written in languages other than English were excluded. Another weakness is that studies not yet published were also excluded (publication bias).

In summary, there appears to be some evidence indicating higher degree of dyslipidemia in patients with OSA, these levels may be correlated to the level of severity of disease as suggested by meta-regression plot for AHI. These findings may explain, at least in part, the mechanism for atherosclerosis leading to cardiovascular disorder in patients with OSA and the common occurrence of systemic complications among these patients. Future studies are needed to further explore the correlation between the level of dyslipidemia and severity of OSA and to determine whether levels of dyslipidemia can be modified by therapeutic interventions in these patients.

\section{REFERENCES}

1. Young T, Palta M, Dempsey J, Skatrud J, Weber S, Badr S. The occurrence of sleep-disordered breathing among middle-aged adults. N Engl J Med 1993;32:1230-5.

2. Guilleminault C, Tilkian A, Dement WC. The sleep apnea syndromes. Annu Rev Med 1976;27:465-84.

3. Nieto FJ, Young TB, Lind BK, et al. Association of sleep-disordered breathing, sleep apnea, and hypertension in a large community-based study. Sleep Heart Health Study. JAMA 2000; 283:1829-36.

4. Peppard PE, Young T, Palta M, et al. Prospective study of the association between sleep-disordered breathing and hypertension. N Engl J Med 2000;342:1378-84.

5. Shahar E, Whitney CW, Redline S, et al. Sleep-disordered breathing and cardiovascular disease: cross-sectional results of the Sleep Heart Health Study. Am J Respir Crit Care Med 2001;163:19-25.

6. Peker $\mathrm{Y}$, Hedner J, Norum J, Kraiczi H, Carlson J. Increased incidence of cardiovascular disease in middle-aged men with obstructive sleep apnea: a 7-year follow-up. Am J Respir Crit Care Med 2002;166:159-65.

7. Imadojemu VA, Gleeson K, Gray KS, Sinoway LI, Leuenberger UA. Obstructive sleep apnea during sleep is associated with peripheral vasoconstriction. Am J Respir Crit Care Med 2002;165:61-6. 
8. Sajkov D, Wang T, Saunders NA, Bune AJ, McEvoy RD. Continuous positive airway pressure treatment improves pulmonary hemodynamics in patients with obstructive sleep apnea. Am J Respir Crit Care Med 2002;166:152-8.

9. Amin RS, Kimball TR, Bean JA, et al. Left ventricular hypertrophy and abnormal ventricular geometry in children and adolescents with obstructive sleep apnea. Am J Respir Crit Care Med 2002;165:1395-9.

10. Rebuffè-Scrive M, Mårin P, Björntorp P. Effect of testosterone on abdominal adipose tissue in men. Int $J$ Obes 1991;15:791-5.

11. Barceló A, Barbé F, Llompart E, et al. Effects of obesity on C-reactive protein level and metabolic disturbances in male patients with obstructive sleep apnea. Am J Med 2004;117:118-21

12. Barceló $A$, Barbé $F$, de la Peña $M$, et al. Insulin resistance and daytime sleepiness in patients with sleep apnoea. Thorax 2008:63:946-50.

13. Bhushan B, Guleria R, Misra A, Pandey RM, Luthra K, Vikram NK. Obstructive sleep apnoea correlates with C-reactive protein in obese Asian Indians. Nutr Metab Cardiovasc Dis 2009;19:184-9.

14. Can M, Açikgöz S, Mungan G, et al. Serum cardiovascular risk factors in obstructive sleep apnea. Chest 2006;129:233-7.

15. Cofta S, Wysocka E, Michalak S, Piorunek T, Batura-Gabryel H, Torlinski L. Endothelium-derived markers and antioxidant status in the blood of obstructive sleep apnea males. Eur J Med Res 2009;14 Suppl 4:49-52.

16. Coughlin SR, Mawdsley L, Mugarza JA, Calverley PM, Wilding JP. Obstructive sleep apnoea is independently associated with an increased prevalence of metabolic syndrome. Eur Heart J 2004;25:735-41.

17. Drager LF, Bortolotto LA, Maki-Nunes $C$, et al. The incremental role of obstructive sleep apnoea on markers of atherosclerosis in patients with metabolic syndrome. Atherosclerosis 2010;208:490-5

18. Gambineri A, Pelusi C, Pasquali R. Testosterone levels in obese male patients with obstructive sleep apnea syndrome: relation to oxygen desaturation, body weight, fat distribution and the metabolic parameters. J Endocrinol Invest 2003:26:493-8.

19. Gasa M, Salord N, Fortuna AM, et al. Obstructive sleep apnoea and metabolic impairment in severe obesity. Eur Respir J 2011;38:1089-97

20. Gruber A, Horwood F, Sithole J, Ali NJ, Idris I. Obstructive sleep apnoea is independently associated with the metabolic syndrome but not insulin resistance state. Cardiovasc Diabetol 2006;5:22.

21. Guill S, Hargens T, Nickols-Richardson S, et al. Early evidence of increased risk for metabolic syndrome in young men with latent obstructive sleep apnea. Metab Syndr Relat Disord 2010;8:33-8

22. lesato K, Tatsumi K, Saibara T, et al. Decreased lipoprotein lipase in obstructive sleep apnea syndrome. Circ J 2007;71:1293-8.

23. Ip MS, Lam KS, Ho C, Tsang KW, Lam W. Serum leptin and vascular risk factors in obstructive sleep apnea. Chest 2000;118:580-6

24. Kono M, Tatsumi K, Saibara T, et al. Obstructive sleep apnea syndrome is associated with some components of metabolic syndrome. Chest 2007;131:1387-92.

25. Lin QC, Zhang XB, Chen GP, Huang DY, Din HB, Tang AZ. Obstructive sleep apnea syndrome is associated with some components of metabolic syndrome in nonobese adults. Sleep Breath 2012;16:571-8.

26. McArdle N, Hillman D, Beilin L, Watts G. Metabolic risk factors for vascular disease in obstructive sleep apnea: a matched controlled study. Am J Respir Crit Care Med 2007;175:190-5.

27. Monneret D, Borel JC, Pepin JL, et al. Pleiotropic role of IGF-I in obesity hypoventilation syndrome. Growth Horm IGF Res 2010;20:127-33

28. Ozol D, Turkay C, Kasapoglu B, Karamanlı H, Yıldırım Z. Relationship between components of metabolic syndrome and polysomnographic findings in obstructive sleep apnea. Metab Syndr Relat Disord 2011;9:13-8

29. Panaree B, Chantana M, Wasana S, Chairat N. Effects of obstructive sleep apnea on serum brain-derived neurotrophic factor protein, cortisol, and lipid levels. Sleep Breath 2011;15:649-56.

30. Peled N, Kassirer M, Shitrit D, et al. The association of OSA with insulin resistance, inflammation and metabolic syndrome. Respir Med 2007;101:1696701

31. Salord N, Mayos M, Miralda R, Perez A. Respiratory sleep disturbances in patients undergoing gastric bypass surgery and their relation to metabolic syndrome. Obes Surg 2009;19:74-9

32. Sánchez-de-la-Torre M, Pierola J, Vidal $C$, et al. Non-synonymous polymorphism in the neuropeptide $\mathrm{S}$ precursor gene and sleep apnea Sleep Breath 2011;15:403-8.

33. Sharma SK, Kumpawat S, Goel A, Banga A, Ramakrishnan L, Chaturvedi P. Obesity, and not obstructive sleep apnea, is responsible for metabolic abnormalities in a cohort with sleep-disordered breathing Sleep Med 2007;8:12-7.
34. Tan KC, Chow WS, Lam JC, et al. MS HDL dysfunction in obstructive sleep apnea. Atherosclerosis 2006;184:377-82

35. Trakada G, Steiropoulos P, Nena E, et al. Plasma visfatin levels in severe obstructive sleep apnea-hypopnea syndrome Sleep Breath 2009;13:349-55

36. Hozo SP, Djulbegovic B, Hozo I. Estimating the mean and variance from the median, range, and the size of a sample. BMC Med Res Method 2005;5:13.

37. Sackett DL, Straus SE, Richardson WS, Rosenberg W, Haynes RB. Evidencebased medicine - How to practice and teach EBM, 2nd ed. Oxford: Churchill Livingstone, 2000:173-75

38. Prospective Studies Collaboration. Blood cholesterol and vascular mortality by age, sex, and blood pressure: a meta-analysis of individual data from 61 prospective studies with 55,000 vascular deaths. Lancet 2007;370:1829-39.

39. Di Angelantonio E, Sarwar N, Perry P, et al. Major lipids, apolipoproteins, and risk of vascular disease. JAMA 2009;302:1993-2000.

40. Baigent $\mathrm{C}$, Blackwell L, Emberson J, et al. Efficacy and safety of more intensive lowering of LDL cholesterol: a meta-analysis of data from 170,000 participants in 26 randomised trials. Lancet 2010;376:1670-81.

41. Emberson JR, Ng LL, Armitage J, Bowman L, Parish S, Collins R. N-terminal pro-B-type natriuretic peptide, vascular disease risk, and cholesterol reduction among 20,536 patients in the MRC/BHF heart protection study. J Am Coll Cardiol 2007;49:311-9.

42. Cleland JGF, McMurray JJV, Kjekshus J, et al.; CORONA Study Group. Plasma concentration of amino-terminal pro-brain natriuretic peptide in chronic heart failure: prediction of cardiovascular events and interaction with the effects of rosuvastatin: a report from CORONA (Controlled Rosuvastatin Multinational Trial in Heart Failure). J Am Coll Cardiol 2009;54:1850-9.

43. Adedayo AM, Olafiranye $O$, Smith $D$, et al. Obstructive sleep apnea and dyslipidemia: evidence and underlying mechanism. Sleep Breath 2014;18:13-8.

44. Arnaud C, Dematteis M, Pepin JL, Baguet JP, Lévy P. Semin Immunopathol 2009;31:113-25.

45. Nadeem R, Molnar J, Madbouly EM, et al. Serum inflammatory markers in obstructive sleep apnea: a meta-analysis. J Clin Sleep Med 2013;9:1003-12

46. Klein RL, Ascencao JL, Mironova M, Huang Y, Lopes-Virella MF. Effect of inflammatory cytokines on the metabolism of low-density lipoproteins by human vascular endothelial cells. Metabolism 2001;50:99-106

47. Börgel J, Sanner BM, Bittlinsky A, et al. Obstructive sleep apnoea and its therapy influence high-density lipoprotein cholesterol serum levels. Eur Respir J 2006:27:121-7

48. Quan SF, Budhiraja R, Clarke DP, et al. Impact of treatment with continuous positive airway pressure (CPAP) on weight in obstructive sleep apnea. $J$ Clin Sleep Med 2013;9:989-93.

49. Fava C, Dorigoni S, Dalle Vedove F, et al. Effect of continuous positive airway pressure (CPAP) on blood pressure in patients with obstructive sleep apnea/ hypopnea. A systematic review and meta-analysis. Chest 2013 Sep 26. [Epub ahead of print].

50. Weinstock TG, Wang X, Rueschman M, et al. A controlled trial of CPAP therapy on metabolic control in individuals with impaired glucose tolerance and sleep apnea. Sleep 2012;35:617-25B.

51. Mota PC, Drummond M, Winck JC, Santos AC, Almeida J, Marques JA. APAP impact on metabolic syndrome in obstructive sleep apnea patients. Sleep Breath 2011;15:665-72.

\section{ACKNOWLEDGMENTS}

The authors express our sincere appreciation to Librarian, Ms. Anne Baker for assistance in acquisition of articles.

\section{SUBMISSION \& CORRESPONDENCE INFORMATION}

Submitted for publication May, 2013

Submitted in final revised form December, 2013

Accepted for publication January, 2014

Address correspondence to: Rashid Nadeem, M.D., Rosalind Franklin University of Medicine and Science, 3333 Green Bay Road, North Chicago, Illinois, 60064; Tel: (847) 578-3000; Fax: (866) 239-8451; E-mail: Nadeem.dr@gmail.com

\section{DISCLOSURE STATEMENT}

This was not an industry supported study. The authors have indicated no financial conflicts of interest. 


\section{APPENDIX}

Figure A1-Total cholesterol, standardized difference in means, OSA versus controls

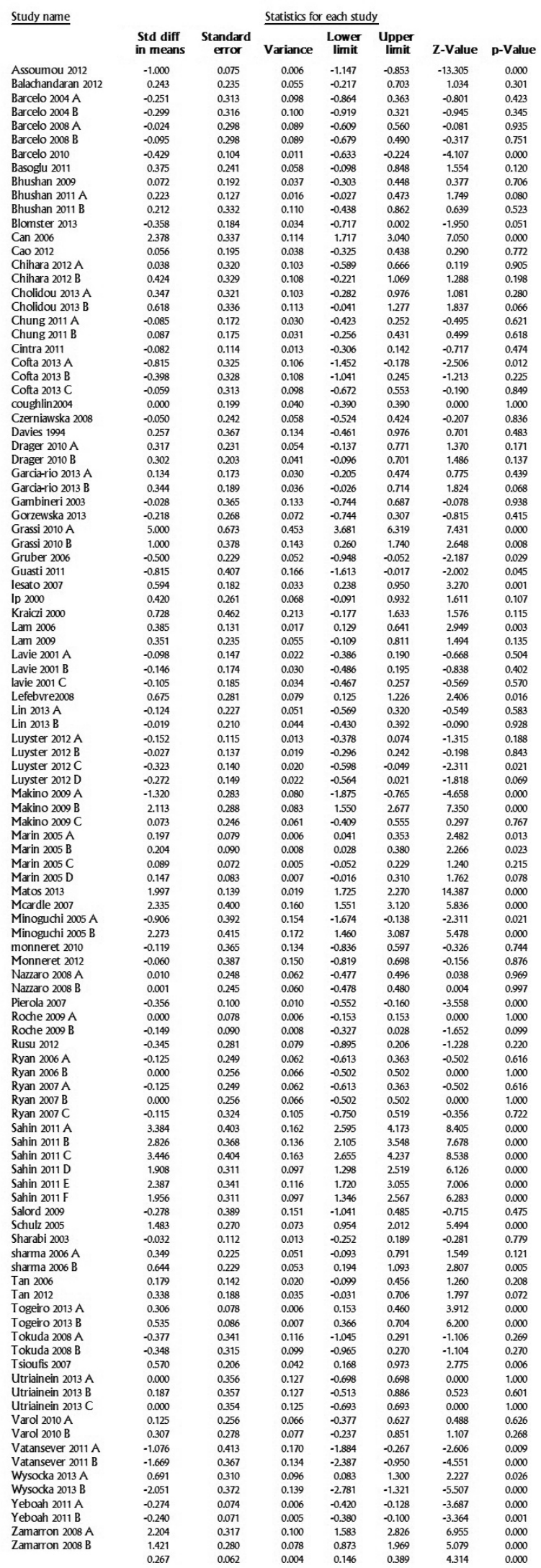

$\underline{\text { Std diff in means and } 95 \% \mathrm{Cl}}$
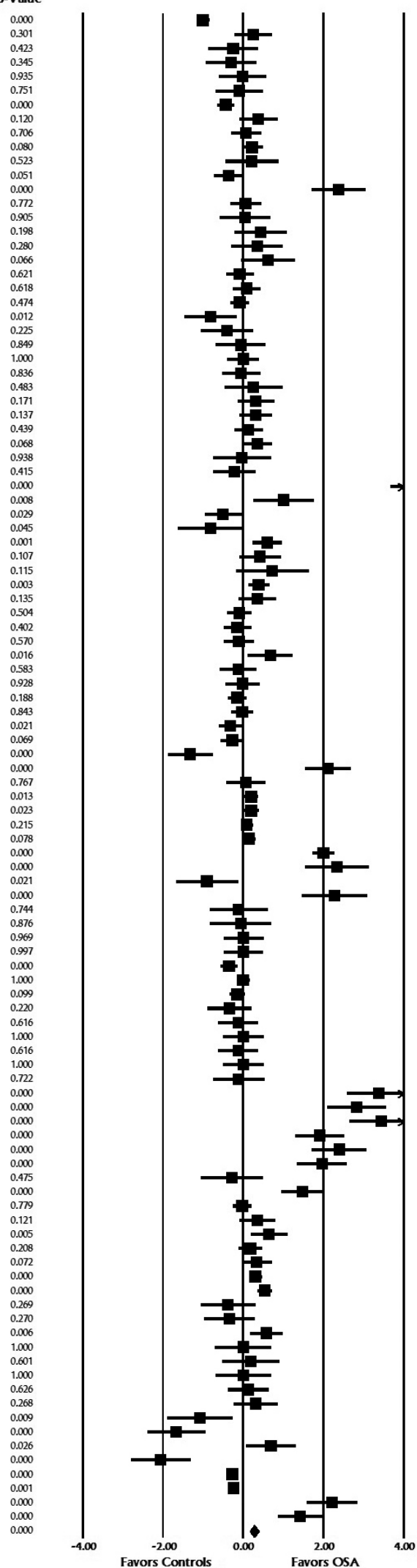
Figure A2-LDL cholesterol, standardized difference in means, OSA versus controls

Study name

\begin{tabular}{|c|c|c|c|c|c|c|c|}
\hline & \multirow[b]{2}{*}{$\begin{array}{l}\text { Std diff } \\
\text { in means }\end{array}$} & \multirow[b]{2}{*}{$\begin{array}{l}\text { Standard } \\
\text { error }\end{array}$} & & & & & \\
\hline & & & Variance & $\begin{array}{c}\text { Lower } \\
\text { limit }\end{array}$ & $\begin{array}{c}\text { Upper } \\
\text { limit }\end{array}$ & Z-Value & p-Value \\
\hline Assoumou 2012 & 1.400 & 0.077 & 0.006 & 1.249 & 1.551 & 18.150 & 0.000 \\
\hline Barccelo 2004 A & 0.026 & 0.312 & 0.097 & -0.585 & 0.638 & 0.085 & 0.932 \\
\hline Barccelo 2004 B & -0.125 & 0.315 & 0.099 & -0.742 & 0.492 & -0.397 & 0.691 \\
\hline Basoglu 2011 & 0.883 & 0.251 & 0.063 & 0.392 & 1.374 & 3.524 & 0.000 \\
\hline CaO 2012 & 0.175 & 0.195 & 0.038 & -0.207 & 0.557 & 0.899 & 0.369 \\
\hline Cholidou 2013 A & 0.269 & 0.320 & 0.102 & -0.359 & 0.896 & 0.839 & 0.401 \\
\hline Cholidou 2013 B & 0.467 & 0.333 & 0.111 & -0.186 & 1.121 & 1.402 & 0.161 \\
\hline Chung 2011 A & -0.173 & 0.172 & 0.030 & -0.511 & 0.165 & -1.003 & 0.316 \\
\hline Chung 2011 B & -0.168 & 0.176 & 0.031 & -0.512 & 0.176 & -0.959 & 0.338 \\
\hline Cintra 2011 & 0.011 & 0.114 & 0.013 & -0.213 & 0.235 & 0.096 & 0.923 \\
\hline Cofta 2013 A & -0.661 & 0.321 & 0.103 & -1.289 & -0.032 & -2.059 & 0.040 \\
\hline Cofta 2013 B & 1.094 & 0.348 & 0.121 & 0.411 & 1.776 & 3.141 & 0.002 \\
\hline Cofta 2013 C & -0.165 & 0.313 & 0.098 & -0.778 & 0.449 & -0.526 & 0.599 \\
\hline Czerniawska 2008 & -0.092 & 0.242 & 0.058 & -0.566 & 0.382 & -0.378 & 0.705 \\
\hline Coughlin 2004 & 0.669 & 0.204 & 0.042 & 0.268 & 1.070 & 3.271 & 0.001 \\
\hline Can 2006 & 2.772 & 0.362 & 0.131 & 2.063 & 3.480 & 7.667 & 0.000 \\
\hline Davies 1994 & 0.372 & 0.368 & 0.136 & -0.350 & 1.094 & 1.011 & 0.312 \\
\hline Drager 2010 & 0.179 & 0.203 & 0.041 & -0.218 & 0.576 & 0.884 & 0.376 \\
\hline Garcia-rio $2013 \mathrm{~A}$ & 0.088 & 0.173 & 0.030 & -0.251 & 0.428 & 0.510 & 0.610 \\
\hline Garcia-rio 2013 B & 0.267 & 0.188 & 0.035 & -0.102 & 0.636 & 1.419 & 0.156 \\
\hline Guasti 2011 & -1.078 & 0.418 & 0.175 & -1.898 & -0.258 & -2.577 & 0.010 \\
\hline Gruber 2006 & 0.000 & 0.225 & 0.051 & -0.441 & 0.441 & 0.000 & 1.000 \\
\hline IP 2000 & 0.372 & 0.260 & 0.068 & -0.138 & 0.883 & 1.429 & 0.153 \\
\hline Kraiczi 2000 & 0.723 & 0.462 & 0.213 & -0.182 & 1.627 & 1.566 & 0.117 \\
\hline Lam 2006 & 0.125 & 0.130 & 0.017 & -0.129 & 0.379 & 0.964 & 0.335 \\
\hline Lam 2009 & 0.491 & 0.236 & 0.056 & 0.028 & 0.954 & 2.079 & 0.038 \\
\hline Lavie $2001 \mathrm{~A}$ & 0.077 & 0.147 & 0.022 & -0.211 & 0.365 & 0.525 & 0.600 \\
\hline Lavie 2001 B & -0.125 & 0.174 & 0.030 & -0.465 & 0.216 & -0.719 & 0.472 \\
\hline Lavie $2001 \mathrm{C}$ & -0.044 & 0.185 & 0.034 & -0.406 & 0.318 & -0.241 & 0.810 \\
\hline Lefebvre 2008 & 0.338 & 0.276 & 0.076 & -0.202 & 0.878 & 1.225 & 0.220 \\
\hline Lin $2013 \mathrm{~A}$ & -0.081 & 0.227 & 0.051 & -0.525 & 0.363 & -0.358 & 0.720 \\
\hline Lin 2013 B & 0.169 & 0.210 & 0.044 & -0.242 & 0.581 & 0.806 & 0.420 \\
\hline Luyster $2012 \mathrm{~A}$ & -0.125 & 0.115 & 0.013 & -0.351 & 0.101 & -1.080 & 0.280 \\
\hline Luyster 2012 B & 0.073 & 0.137 & 0.019 & -0.196 & 0.342 & 0.531 & 0.596 \\
\hline Luyster 2012 C & -0.194 & 0.139 & 0.019 & -0.467 & 0.079 & -1.390 & 0.165 \\
\hline Luyster 2012 D & -0.117 & 0.149 & 0.022 & -0.408 & 0.175 & -0.782 & 0.434 \\
\hline Matos 2013 & 1.366 & 0.126 & 0.016 & 1.119 & 1.613 & 10.848 & 0.000 \\
\hline Minoguchi $2005 \mathrm{~A}$ & -0.077 & 0.374 & 0.140 & -0.809 & 0.655 & -0.207 & 0.836 \\
\hline Minoguchi 2005 B & 0.962 & 0.343 & 0.118 & 0.289 & 1.635 & 2.803 & 0.005 \\
\hline Monneret 2012 & -0.247 & 0.388 & 0.150 & -1.007 & 0.514 & -0.636 & 0.525 \\
\hline Mcardle 2007 & 1.985 & 0.377 & 0.142 & 1.246 & 2.724 & 5.265 & 0.000 \\
\hline Monneret2010 & -0.333 & 0.368 & 0.135 & -1.054 & 0.387 & -0.907 & 0.365 \\
\hline Nazzaro $2008 \mathrm{~A}$ & 0.293 & 0.249 & 0.062 & -0.196 & 0.782 & 1.174 & 0.240 \\
\hline Nazzaro 2008 B & -0.187 & 0.245 & 0.060 & -0.667 & 0.294 & -0.761 & 0.446 \\
\hline Panaree2011 & 0.114 & 0.260 & 0.067 & -0.395 & 0.623 & 0.439 & 0.660 \\
\hline Rusu 2012 & 0.064 & 0.280 & 0.078 & -0.484 & 0.612 & 0.230 & 0.818 \\
\hline Ryan $2006 \mathrm{~A}$ & -0.404 & 0.251 & 0.063 & -0.896 & 0.089 & -1.607 & 0.108 \\
\hline Ryan 2006 B & -0.138 & 0.256 & 0.066 & -0.640 & 0.365 & -0.538 & 0.591 \\
\hline Ryan $2007 \mathrm{~A}$ & -0.404 & 0.251 & 0.063 & -0.896 & 0.089 & -1.607 & 0.108 \\
\hline Ryan 2007 B & -0.138 & 0.256 & 0.066 & -0.640 & 0.365 & -0.538 & 0.591 \\
\hline Ryan 2007 C & -0.293 & 0.325 & 0.106 & -0.931 & 0.344 & -0.902 & 0.367 \\
\hline Roche $2009 \mathrm{~A}$ & 0.099 & 0.078 & 0.006 & -0.055 & 0.252 & 1.262 & 0.207 \\
\hline Roche $2009 \mathrm{~B}$ & 0.038 & 0.090 & 0.008 & -0.139 & 0.214 & 0.415 & 0.678 \\
\hline Schulz 2005 & -1.354 & 0.265 & 0.070 & -1.873 & -0.834 & -5.108 & 0.000 \\
\hline Sharabi 2003 & -0.056 & 0.112 & 0.013 & -0.276 & 0.164 & -0.498 & 0.618 \\
\hline Sahin $2011 \mathrm{~A}$ & 3.018 & 0.378 & 0.143 & 2.278 & 3.758 & 7.993 & 0.000 \\
\hline Sahin 2011 B & 2.952 & 0.376 & 0.142 & 2.214 & 3.690 & 7.843 & 0.000 \\
\hline Sahin $2011 \mathrm{C}$ & 3.243 & 0.390 & 0.152 & 2.480 & 4.007 & 8.324 & 0.000 \\
\hline Sahin 2011 D & 1.790 & 0.306 & 0.093 & 1.191 & 2.389 & 5.857 & 0.000 \\
\hline Sahin $2011 \mathrm{E}$ & 2.017 & 0.320 & 0.102 & 1.390 & 2.644 & 6.306 & 0.000 \\
\hline Sahin $2011 \mathrm{~F}$ & 2.034 & 0.315 & 0.099 & 1.415 & 2.652 & 6.447 & 0.000 \\
\hline Sharma $2006 \mathrm{~A}$ & 0.455 & 0.226 & 0.051 & 0.012 & 0.899 & 2.011 & 0.044 \\
\hline Sharma 2006 B & 0.796 & 0.232 & 0.054 & 0.340 & 1.251 & 3.425 & 0.001 \\
\hline Salord 2009 & -0.211 & 0.388 & 0.151 & -0.972 & 0.550 & -0.544 & 0.587 \\
\hline Tan 2006 & 0.111 & 0.142 & 0.020 & -0.167 & 0.388 & 0.781 & 0.435 \\
\hline Tan 2012 & 0.418 & 0.188 & 0.035 & 0.049 & 0.787 & 2.222 & 0.026 \\
\hline Togeiro $2012 \mathrm{~A}$ & 0.267 & 0.078 & 0.006 & 0.114 & 0.421 & 3.420 & 0.001 \\
\hline Togeiro 2012 B & 0.491 & 0.086 & 0.007 & 0.322 & 0.659 & 5.699 & 0.000 \\
\hline Tokuda $2008 \mathrm{~A}$ & -0.179 & 0.339 & 0.115 & -0.843 & 0.484 & -0.530 & 0.596 \\
\hline Tokuda 2008 B & -0.308 & 0.315 & 0.099 & -0.925 & 0.308 & -0.981 & 0.327 \\
\hline Tsioufis 2007 & 1.087 & 0.216 & 0.047 & 0.664 & 1.510 & 5.036 & 0.000 \\
\hline Utriainen $2013 \mathrm{~A}$ & -0.120 & 0.356 & 0.127 & -0.818 & 0.579 & -0.336 & 0.737 \\
\hline Utriainen 2013 B & 0.303 & 0.358 & 0.128 & -0.399 & 1.004 & 0.846 & 0.398 \\
\hline Utriainen 2013 C & 0.103 & 0.354 & 0.125 & -0.590 & 0.797 & 0.292 & 0.770 \\
\hline Vatansever $2011 \mathrm{~A}$ & -0.271 & 0.392 & 0.154 & -1.039 & 0.498 & -0.690 & 0.490 \\
\hline Vatansever 2011 B & -1.679 & 0.367 & 0.135 & -2.399 & -0.959 & -4.572 & 0.000 \\
\hline Varol $2010 \mathrm{~A}$ & 0.177 & 0.256 & 0.066 & -0.326 & 0.679 & 0.689 & 0.491 \\
\hline Varol 2010 B & 0.162 & 0.276 & 0.076 & -0.380 & 0.704 & 0.586 & 0.558 \\
\hline Wysocka 2013 A & 1.164 & 0.326 & 0.106 & 0.525 & 1.804 & 3.571 & 0.000 \\
\hline Wysocka 2013 B & -0.693 & 0.310 & 0.096 & -1.302 & -0.085 & -2.234 & 0.026 \\
\hline Yeboah $2011 \mathrm{~A}$ & -0.269 & 0.074 & 0.006 & -0.414 & -0.123 & -3.617 & 0.000 \\
\hline Yeboah 2011 B & -0.171 & 0.071 & 0.005 & -0.311 & -0.031 & -2.396 & 0.017 \\
\hline & 0.296 & 0.071 & 0.005 & 0.156 & 0.436 & 4.143 & 0.000 \\
\hline
\end{tabular}

$\underline{\text { Std diff in means and } 95 \% \mathrm{Cl}}$

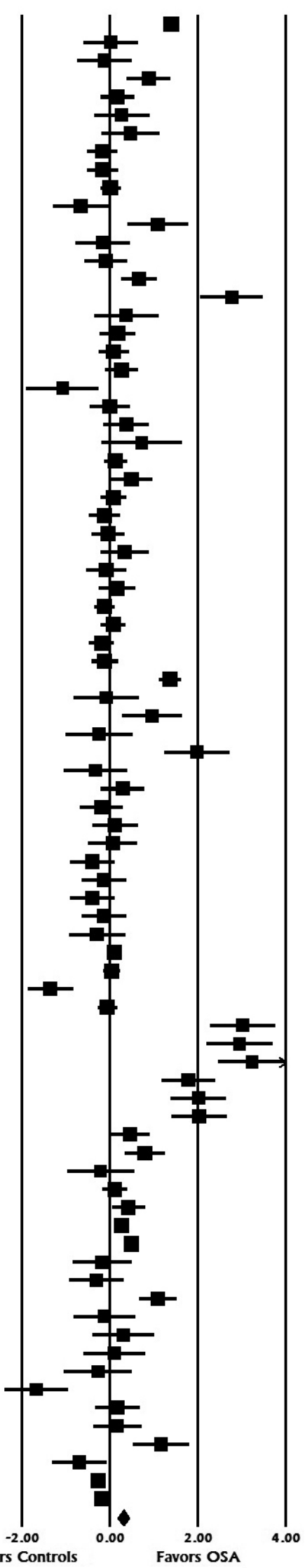


Figure A3-HDL cholesterol, standardized difference in means, OSA versus controls

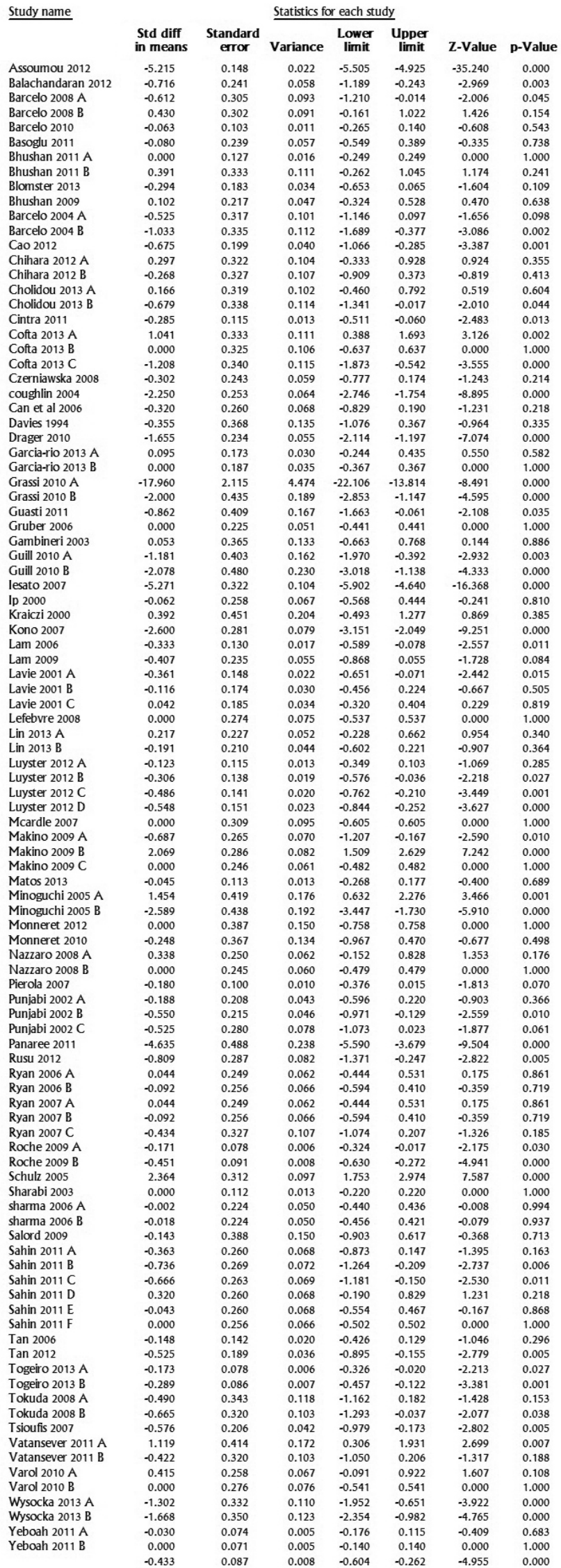

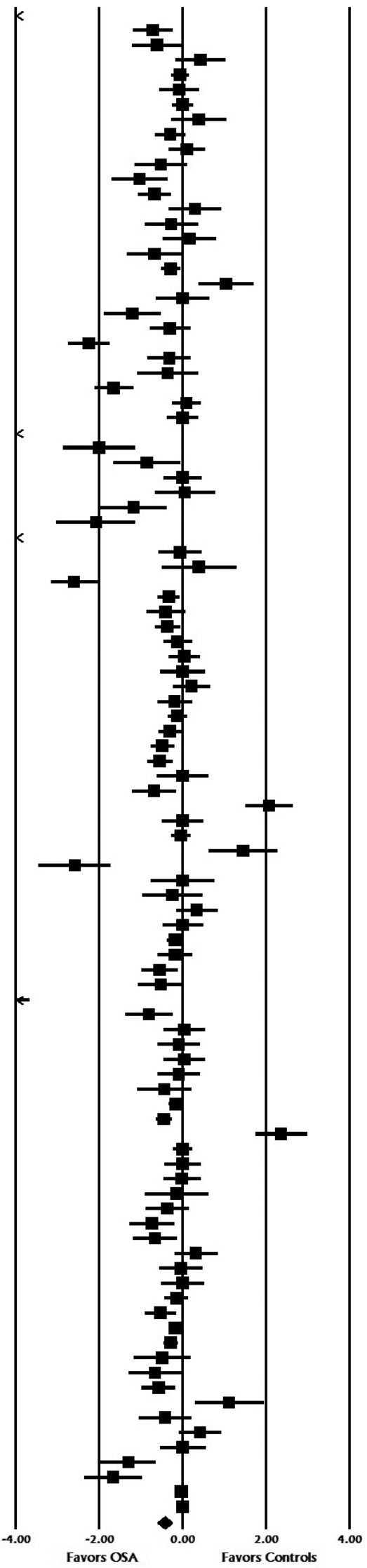


Figure A4-Triglycerides, standardized difference in means, OSA versus controls

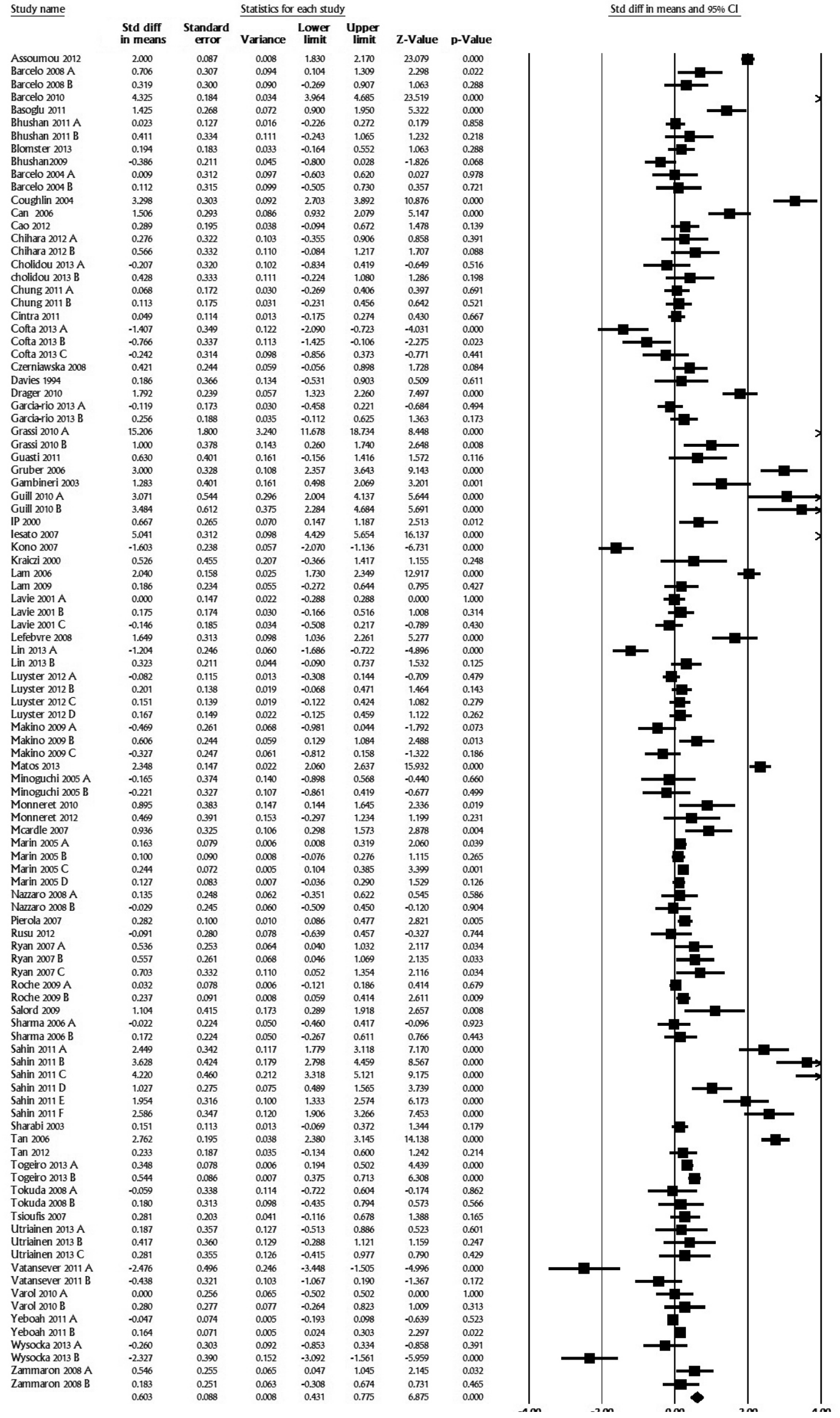


Figure A5-TC sensitivity analysis

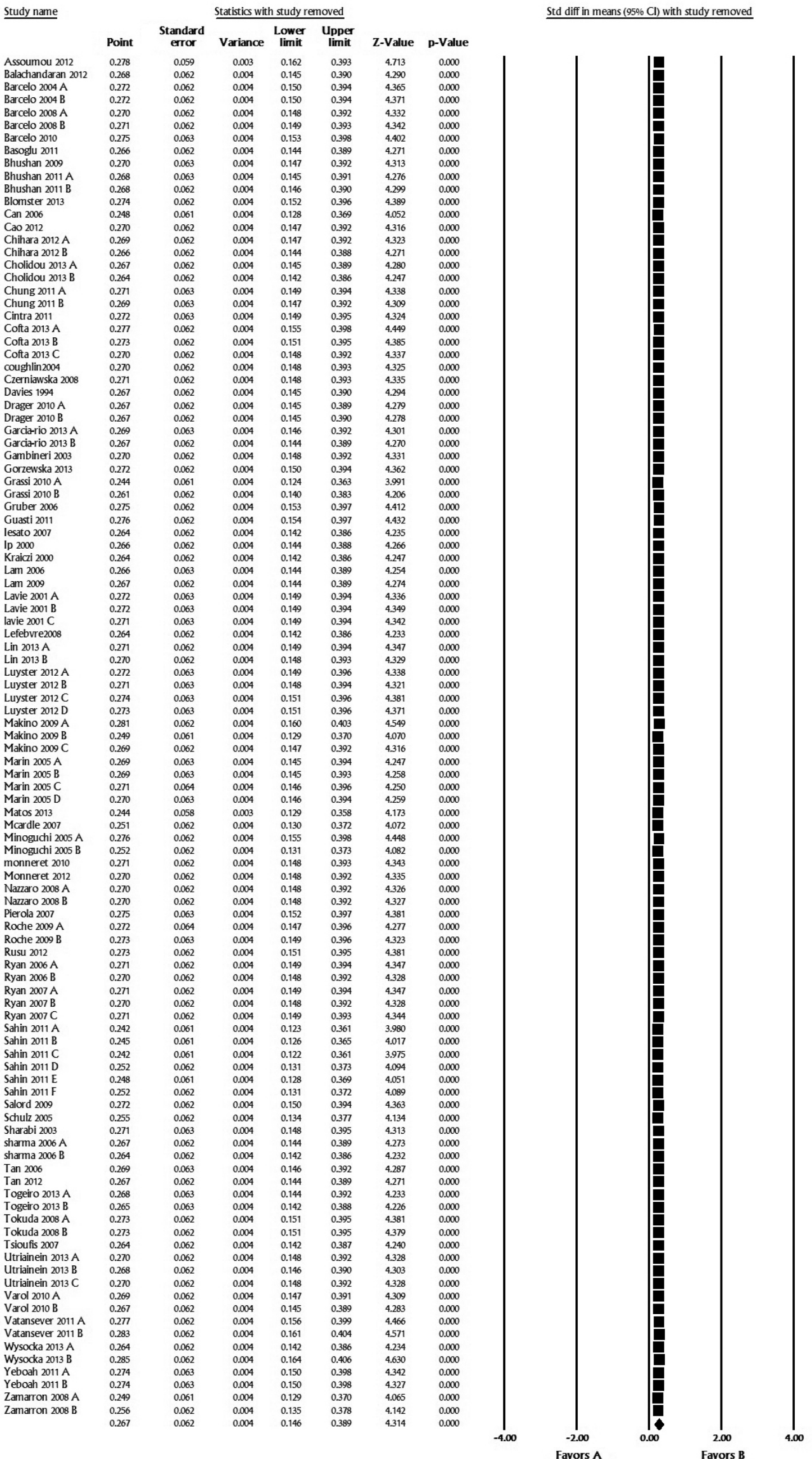


Figure A6—LDL sensitivity analysis

Study name

\begin{tabular}{|c|c|c|c|c|c|c|c|}
\hline & Point & $\begin{array}{l}\text { Standard } \\
\text { error }\end{array}$ & Variance & $\begin{array}{c}\text { Lower } \\
\text { limit }\end{array}$ & $\begin{array}{c}\text { Upper } \\
\text { limit }\end{array}$ & Z-Value & p-Value \\
\hline Assoumou 2012 & 0.275 & 0.065 & 0.004 & 0.148 & 0.402 & 4.250 & 0.000 \\
\hline Barccelo 2004 A & 0.299 & 0.072 & 0.005 & 0.158 & 0.440 & 4.155 & 0.000 \\
\hline Barccelo 2004 B & 0.301 & 0.072 & 0.005 & 0.160 & 0.442 & 4.181 & 0.000 \\
\hline Basoglu 2011 & 0.288 & 0.072 & 0.005 & 0.148 & 0.429 & 4.016 & 0.000 \\
\hline Саo 2012 & 0.298 & 0.072 & 0.005 & 0.156 & 0.439 & 4.120 & 0.000 \\
\hline Cholidou 2013 A & 0.296 & 0.072 & 0.005 & 0.155 & 0.437 & 4.116 & 0.000 \\
\hline Cholidou 2013 B & 0.294 & 0.072 & 0.005 & 0.153 & 0.435 & 4.087 & 0.000 \\
\hline Chung 2011 A & 0.302 & 0.072 & 0.005 & 0.161 & 0.444 & 4.191 & 0.000 \\
\hline Chung 2011 B & 0.302 & 0.072 & 0.005 & 0.161 & 0.444 & 4.190 & 0.000 \\
\hline Cintra 2011 & 0.300 & 0.073 & 0.005 & 0.158 & 0.443 & 4.128 & 0.000 \\
\hline Cofta $2013 \mathrm{~A}$ & 0.307 & 0.072 & 0.005 & 0.166 & 0.447 & 4.277 & 0.000 \\
\hline Cofta 2013 B & 0.287 & 0.072 & 0.005 & 0.146 & 0.428 & 4.003 & 0.000 \\
\hline Cofta 2013 C & 0.301 & 0.072 & 0.005 & 0.160 & 0.442 & 4.188 & 0.000 \\
\hline Czerniawska 2008 & 0.301 & 0.072 & 0.005 & 0.160 & 0.442 & 4.176 & 0.000 \\
\hline Coughlin 2004 & 0.291 & 0.072 & 0.005 & 0.150 & 0.432 & 4.040 & 0.000 \\
\hline Can 2006 & 0.269 & 0.070 & 0.005 & 0.131 & 0.406 & 3.826 & 0.000 \\
\hline Davies 1994 & 0.295 & 0.072 & 0.005 & 0.154 & 0.436 & 4.104 & 0.000 \\
\hline Drager 2010 & 0.298 & 0.072 & 0.005 & 0.156 & 0.439 & 4.121 & 0.000 \\
\hline Garcia-rio 2013 A & 0.299 & 0.072 & 0.005 & 0.157 & 0.441 & 4.133 & 0.000 \\
\hline Garcia-rio 2013 B & 0.296 & 0.072 & 0.005 & 0.155 & 0.438 & 4.102 & 0.000 \\
\hline Guasti 2011 & 0.309 & 0.072 & 0.005 & 0.169 & 0.449 & 4.323 & 0.000 \\
\hline Gruber 2006 & 0.300 & 0.072 & 0.005 & 0.158 & 0.441 & 4.158 & 0.000 \\
\hline IP 2000 & 0.295 & 0.072 & 0.005 & 0.154 & 0.436 & 4.095 & 0.000 \\
\hline Kraiczi 2000 & 0.292 & 0.072 & 0.005 & 0.151 & 0.433 & 4.067 & 0.000 \\
\hline Lam 2006 & 0.299 & 0.073 & 0.005 & 0.156 & 0.441 & 4.111 & 0.000 \\
\hline Lam 2009 & 0.293 & 0.072 & 0.005 & 0.152 & 0.435 & 4.072 & 0.000 \\
\hline Lavie $2001 \mathrm{~A}$ & 0.299 & 0.072 & 0.005 & 0.157 & 0.441 & 4.129 & 0.000 \\
\hline Lavie 2001 B & 0.302 & 0.072 & 0.005 & 0.160 & 0.443 & 4.180 & 0.000 \\
\hline Lavie $2001 \mathrm{C}$ & 0.301 & 0.072 & 0.005 & 0.159 & 0.442 & 4.163 & 0.000 \\
\hline Lefebvre 2008 & 0.295 & 0.072 & 0.005 & 0.154 & 0.437 & 4.102 & 0.000 \\
\hline Lin $2013 \mathrm{~A}$ & 0.301 & 0.072 & 0.005 & 0.160 & 0.442 & 4.174 & 0.000 \\
\hline Lin 2013 B & 0.298 & 0.072 & 0.005 & 0.156 & 0.439 & 4.124 & 0.000 \\
\hline Luyster $2012 \mathrm{~A}$ & 0.302 & 0.073 & 0.005 & 0.160 & 0.444 & 4.165 & 0.000 \\
\hline Luyster 2012 B & 0.299 & 0.073 & 0.005 & 0.157 & 0.441 & 4.126 & 0.000 \\
\hline Luyster $2012 \mathrm{C}$ & 0.303 & 0.072 & 0.005 & 0.161 & 0.444 & 4.192 & 0.000 \\
\hline Luyster 2012 D & 0.302 & 0.072 & 0.005 & 0.160 & 0.443 & 4.174 & 0.000 \\
\hline Matos 2013 & 0.279 & 0.070 & 0.005 & 0.143 & 0.416 & 4.006 & 0.000 \\
\hline Minoguchi 2005 A & 0.300 & 0.072 & 0.005 & 0.159 & 0.441 & 4.171 & 0.000 \\
\hline Minoguchi 2005 B & 0.288 & 0.072 & 0.005 & 0.148 & 0.429 & 4.019 & 0.000 \\
\hline Monneret 2012 & 0.301 & 0.072 & 0.005 & 0.161 & 0.442 & 4.197 & 0.000 \\
\hline Mcardle 2007 & 0.278 & 0.071 & 0.005 & 0.138 & 0.417 & 3.905 & 0.000 \\
\hline Monneret2010 & 0.303 & 0.072 & 0.005 & 0.162 & 0.443 & 4.212 & 0.000 \\
\hline Nazzaro 2008 A & 0.296 & 0.072 & 0.005 & 0.155 & 0.437 & 4.107 & 0.000 \\
\hline Nazzaro 2008 B & 0.302 & 0.072 & 0.005 & 0.161 & 0.443 & 4.195 & 0.000 \\
\hline Panaree2011 & 0.298 & 0.072 & 0.005 & 0.157 & 0.439 & 4.139 & 0.000 \\
\hline Rusu 2012 & 0.299 & 0.072 & 0.005 & 0.158 & 0.440 & 4.148 & 0.000 \\
\hline Ryan 2006 A & 0.305 & 0.072 & 0.005 & 0.164 & 0.445 & 4.239 & 0.000 \\
\hline Ryan 2006 B & 0.301 & 0.072 & 0.005 & 0.160 & 0.442 & 4.185 & 0.000 \\
\hline Ryan 2007 A & 0.305 & 0.072 & 0.005 & 0.164 & 0.445 & 4.239 & 0.000 \\
\hline Ryan 2007 B & 0.301 & 0.072 & 0.005 & 0.160 & 0.442 & 4.185 & 0.000 \\
\hline Ryan 2007 C & 0.303 & 0.072 & 0.005 & 0.162 & 0.443 & 4.210 & 0.000 \\
\hline Roche $2009 \mathrm{~A}$ & 0.300 & 0.074 & 0.005 & 0.155 & 0.444 & 4.059 & 0.000 \\
\hline Roche 2009 B & 0.300 & 0.073 & 0.005 & 0.157 & 0.444 & 4.097 & 0.000 \\
\hline Schulz 2005 & 0.316 & 0.071 & 0.005 & 0.177 & 0.454 & 4.456 & 0.000 \\
\hline Sharabi 2003 & 0.301 & 0.073 & 0.005 & 0.159 & 0.444 & 4.144 & 0.000 \\
\hline Sahin $2011 \mathrm{~A}$ & 0.267 & 0.070 & 0.005 & 0.129 & 0.404 & 3.809 & 0.000 \\
\hline Sahin 2011 B & 0.267 & 0.070 & 0.005 & 0.130 & 0.405 & 3.814 & 0.000 \\
\hline Sahin $2011 \mathrm{C}$ & 0.265 & 0.070 & 0.005 & 0.128 & 0.402 & 3.793 & 0.000 \\
\hline Sahin 2011 D & 0.278 & 0.071 & 0.005 & 0.139 & 0.417 & 3.912 & 0.000 \\
\hline Sahin $2011 \mathrm{E}$ & 0.276 & 0.071 & 0.005 & 0.137 & 0.415 & 3.890 & 0.000 \\
\hline Sahin $2011 \mathrm{~F}$ & 0.275 & 0.071 & 0.005 & 0.137 & 0.414 & 3.888 & 0.000 \\
\hline Sharma 2006 A & 0.294 & 0.072 & 0.005 & 0.153 & 0.435 & 4.076 & 0.000 \\
\hline Sharma 2006 B & 0.289 & 0.072 & 0.005 & 0.149 & 0.430 & 4.025 & 0.000 \\
\hline Salord 2009 & 0.301 & 0.072 & 0.005 & 0.160 & 0.442 & 4.191 & 0.000 \\
\hline Tan 2006 & 0.299 & 0.073 & 0.005 & 0.157 & 0.441 & 4.119 & 0.000 \\
\hline Tan 2012 & 0.294 & 0.072 & 0.005 & 0.153 & 0.436 & 4.076 & 0.000 \\
\hline Togeiro $2012 \mathrm{~A}$ & 0.297 & 0.074 & 0.005 & 0.152 & 0.442 & 4.021 & 0.000 \\
\hline Togeiro 2012 B & 0.294 & 0.073 & 0.005 & 0.150 & 0.437 & 4.010 & 0.000 \\
\hline Tokuda $2008 \mathrm{~A}$ & 0.301 & 0.072 & 0.005 & 0.160 & 0.442 & 4.189 & 0.000 \\
\hline Tokuda 2008 B & 0.303 & 0.072 & 0.005 & 0.162 & 0.444 & 4.213 & 0.000 \\
\hline Tsioufis 2007 & 0.285 & 0.072 & 0.005 & 0.145 & 0.426 & 3.985 & 0.000 \\
\hline Utriainen $2013 \mathrm{~A}$ & 0.300 & 0.072 & 0.005 & 0.159 & 0.441 & 4.179 & 0.000 \\
\hline Utriainen 2013 B & 0.296 & 0.072 & 0.005 & 0.155 & 0.437 & 4.114 & 0.000 \\
\hline Utriainen 2013 C & 0.298 & 0.072 & 0.005 & 0.157 & 0.439 & 4.144 & 0.000 \\
\hline Vatansever $2011 \mathrm{~A}$ & 0.302 & 0.072 & 0.005 & 0.161 & 0.442 & 4.200 & 0.000 \\
\hline Vatansever 2011 B & 0.316 & 0.071 & 0.005 & 0.177 & 0.455 & 4.457 & 0.000 \\
\hline Varol $2010 \mathrm{~A}$ & 0.297 & 0.072 & 0.005 & 0.156 & 0.439 & 4.127 & 0.000 \\
\hline Varol 2010 B & 0.298 & 0.072 & 0.005 & 0.156 & 0.439 & 4.131 & 0.000 \\
\hline Wysocka 2013 A & 0.286 & 0.072 & 0.005 & 0.145 & 0.426 & 3.990 & 0.000 \\
\hline Wysocka 2013 B & 0.307 & 0.072 & 0.005 & 0.167 & 0.448 & 4.286 & 0.000 \\
\hline Yeboah 2011 A & 0.304 & 0.072 & 0.005 & 0.162 & 0.446 & 4.200 & 0.000 \\
\hline \multirow{2}{*}{ Yeboah 2011 B } & 0.303 & 0.073 & 0.005 & 0.160 & 0.447 & 4.146 & 0.000 \\
\hline & & & & & & & \\
\hline
\end{tabular}

Std diff in means $(95 \% \mathrm{Cl})$ with study removed
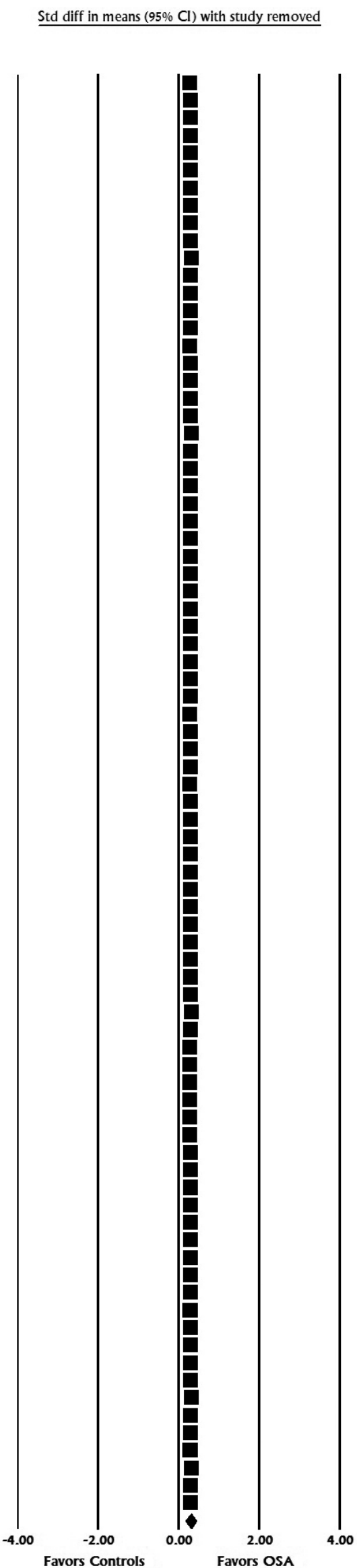
Figure A7-HDL sensitivity analysis

Study name

\begin{tabular}{|c|c|c|}
\hline & Point & $\begin{array}{c}\text { Standard } \\
\text { error }\end{array}$ \\
\hline Assoumou 2012 & -0.191 & 0.060 \\
\hline Balachandaran 2012 & -0.291 & 0.108 \\
\hline Barcelo 2008 A & -0.293 & 0.108 \\
\hline Barcelo 2008 B & -0.308 & 0.108 \\
\hline Barcelo 2010 & -0.302 & 0.110 \\
\hline Basoglu 2011 & -0.301 & 0.108 \\
\hline Bhushan $2011 \mathrm{~A}$ & -0.303 & 0.109 \\
\hline Bhushan 2011 B & -0.307 & 0.108 \\
\hline Blomster 2013 & -0.298 & 0.109 \\
\hline CaO 2012 & -0.291 & 0.109 \\
\hline Chihara 2012 A & -0.306 & 0.108 \\
\hline Chihara 2012 B & -0.298 & 0.108 \\
\hline Cholidou 2013 A & -0.304 & 0.108 \\
\hline Cholidou 2013 B & -0.292 & 0.108 \\
\hline Cintra 2011 & -0.298 & 0.110 \\
\hline Cofta 2013 A & -0.316 & 0.108 \\
\hline Cofta 2013 B & -0.302 & 0.108 \\
\hline Cofta 2013 C & -0.284 & 0.108 \\
\hline Czerniawska 2008 & -0.297 & 0.108 \\
\hline Davies 1994 & -0.296 & 0.108 \\
\hline Drager 2010 & -0.276 & 0.107 \\
\hline Garciar-rio 2013 A & -0.304 & 0.109 \\
\hline Garcia-rio 2013 B & -0.302 & 0.109 \\
\hline Grassi 2010 A & -0.258 & 0.105 \\
\hline Grassi 2010 B & -0.275 & 0.108 \\
\hline Guasti 2011 & -0.290 & 0.108 \\
\hline Kraiczi 2000 & -0.306 & 0.108 \\
\hline Lam 2006 & -0.297 & 0.110 \\
\hline Lam 2009 & -0.296 & 0.109 \\
\hline Lavie $2001 \mathrm{~A}$ & -0.297 & 0.109 \\
\hline Lavie 2001 B & -0.300 & 0.109 \\
\hline Lavie 2001 C & -0.303 & 0.109 \\
\hline Lefebvre 2008 & -0.302 & 0.108 \\
\hline Lin 2013 A & -0.305 & 0.108 \\
\hline Lin 2013 B & -0.299 & 0.109 \\
\hline Luyster $2012 \mathrm{~A}$ & -0.301 & 0.110 \\
\hline Luyster 2012 B & -0.298 & 0.109 \\
\hline Luyster $2012 \mathrm{C}$ & -0.295 & 0.109 \\
\hline Luyster 2012 D & -0.294 & 0.109 \\
\hline Makino 2009 A & -0.291 & 0.108 \\
\hline Makino 2009 B & -0.332 & 0.106 \\
\hline Makino 2009 C & -0.302 & 0.108 \\
\hline Matos 2013 & -0.302 & 0.110 \\
\hline Minoguchi $2005 \mathrm{~A}$ & -0.320 & 0.108 \\
\hline Minoguchi 2005 B & -0.267 & 0.107 \\
\hline Monneret 2012 & -0.301 & 0.108 \\
\hline Pierola 2007 & -0.300 & 0.110 \\
\hline Punjabi $2002 \mathrm{~A}$ & -0.299 & 0.109 \\
\hline Punjabi 2002 B & -0.293 & 0.109 \\
\hline Punjabi 2002 C & -0.294 & 0.108 \\
\hline Rusu 2012 & -0.290 & 0.108 \\
\hline Ryan $2006 \mathrm{~A}$ & -0.303 & 0.108 \\
\hline Ryan 2006 B & -0.300 & 0.108 \\
\hline Ryan $2007 \mathrm{~A}$ & -0.303 & 0.108 \\
\hline Ryan 2007 B & -0.300 & 0.108 \\
\hline Ryan 2007 C & -0.295 & 0.108 \\
\hline Schulz 2005 & -0.335 & 0.106 \\
\hline Sharabi 2003 & -0.303 & 0.110 \\
\hline Tan 2012 & -0.294 & 0.109 \\
\hline Togeiro $2013 \mathrm{~A}$ & -0.301 & 0.112 \\
\hline Togeiro 2013 B & -0.299 & 0.111 \\
\hline Tokuda $2008 \mathrm{~A}$ & -0.294 & 0.108 \\
\hline Tokuda 2008 B & -0.292 & 0.108 \\
\hline Vatansever $2011 \mathrm{~A}$ & -0.316 & 0.108 \\
\hline Vatansever 2011 B & -0.295 & 0.108 \\
\hline Yeboah $2011 \mathrm{~A}$ & -0.304 & 0.112 \\
\hline \multirow[t]{2}{*}{ Yeboah 2011 B } & -0.304 & 0.112 \\
\hline & -0.297 & 0.107 \\
\hline
\end{tabular}

Statistics with study removed

$\begin{array}{ccc}\text { Variance } & \begin{array}{c}\text { Lower } \\ \text { limit }\end{array} & \begin{array}{c}\text { Up } \\ \text { lim }\end{array} \\ 0.004 & -0.308 & -0.07 \\ 0.012 & -0.503 & -0 . \\ 0.012 & -0.505 & -0.0 \\ 0.012 & -0.520 & -0.09 \\ 0.012 & -0.518 & -0.0 \\ 0.012 & -0.513 & -0.0 \\ 0.012 & -0.517 & -0.0 \\ 0.012 & -0.519 & -0.095 \\ 0.012 & -0.511 & -0.004\end{array}$

\section{Upper}

-0.073
-0.078

$-0.080$

$-0.096$

$-0.086$

$-0.088$

$-0.084$

$-0.079$

-0.094
-0.085

-0.085
-0.092

$-0.080$

$-0.083$

$-0.105$

$-0.089$

$-0.072$

$-0.084$

$-0.065$

$-0.091$

$-0.089$

$-0.052$

-0.064
-0.078

$-0.094$

$-0.083$

$-0.083$

$-0.083$

-0.087
-0.090

$-0.089$

$-0.093$

$-0.086$

-0.086
-0.083

-0.083
-0.081

$-0.080$

$-0.079$

$-0.124$

$-0.089$

-0.087
-0.110

$-0.057$

$-0.089$

$-0.084$

$-0.086$

$-0.081$

-0.081
-0.077

$-0.090$

$-0.088$

$-0.090$

$-0.088$

$-0.083$

$-0.088$

$-0.081$

$-0.082$

-0.081
-0.082

-0.082
-0.080

$-0.105$

$-0.083$

$-0.084$

-0.085
-0.087

Z-Value
-3.181
-2.683
-2.702
-2.848
-2.742
-2.772
-2.766
-2.841
-2.735
-2.684
-2.828
-2.750
-2.809
-2.696
-2.714
-2.936
-2.786
-2.630
-2.740
-2.740
-2.567
-2.793
-2.780
-2.454
-2.552
-2.679
-2.834
-2.715
-2.725
-2.717
-2.760
-2.786
-2.785
-2.817
-2.753
-2.739
-2.722
-2.697
-2.692
-2.689
-3.125
-2.784
-2.752
-2.978
-2.488
-2.786
-2.719
-2.753
-2.703
-2.712
-2.692
-2.675
-2.721
-2.697
-2.771
-2.791
-2.771
-2.727
-2.729
-2.712
-2.771

p-Value

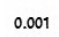

0.001
0.007
0.007

0.007

0.004

0.006

0.006

0.004

0.006
0.007
0.005

0.006
0.005

0.007

0.007

0.003

0.005

0.009

0.006

0.010

0.005

0.005
0.014

0.014
0.011

0.007

0.005
0.007
0.006

0.006

0.007
0.006
0.005

0.005

0.005
0.005
0.006

0.006

0.006

0.006

0.007

0.007
0.007
0.007

0.007

0.002
0.005
0.006
0.003

0.003

0.013

0.005

0.007

0.007
0.006
0.007
0.007

0.007

0.005

0.006

0.005

0.006
0.006

0.002

0.006

0.006
0.007
0.007

0.007

0.007

0.007
0.007
0.003

0.003

0.006
0.007

0.007

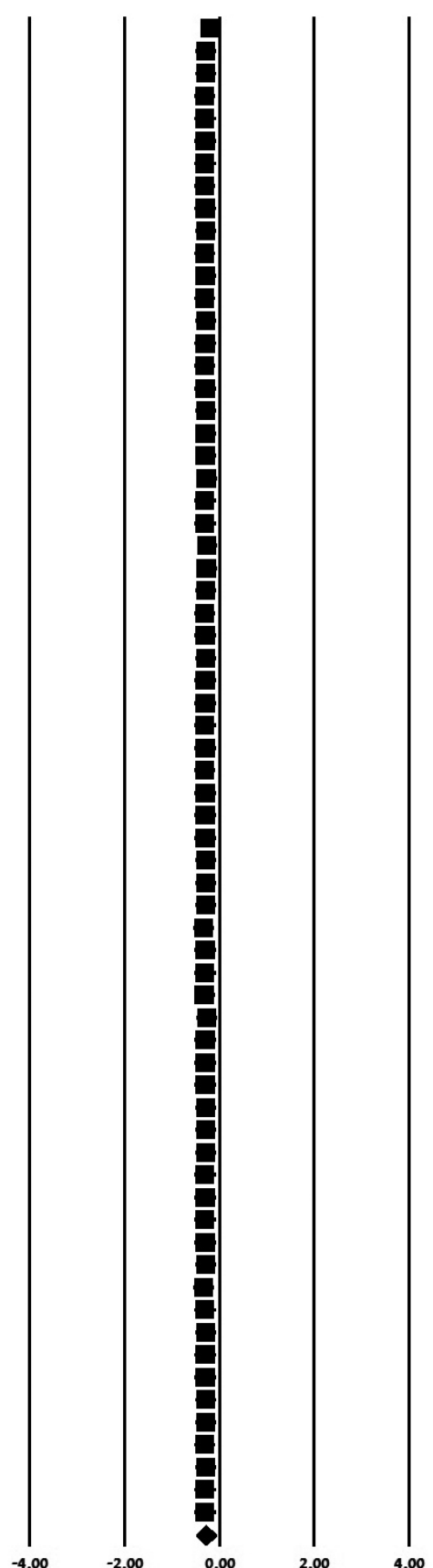

Favors OSA Favors Controls 
Figure A8-TG sensitivity analysis

$\underline{\text { Study name }}$

Assoumou 2012 Barcelo 2008 A Barcelo 2008 Barcelo 2010 0.595
$-\quad 0.510$ Bhushan 2011 B 0.605 Blomster $2013 \quad 0.608$ Barcelo 2004 A 0609 Barcelo 2004 B 0.609 Coughlin 2004 Can $2006 \quad 0.595$ Cao 2012 Chihara 2012 A $\quad 0.607$ Chihara 2012 B $\quad 0.604$ Cholidou $2013 \mathrm{~A} \quad 0.611$ cholidou 2013 B $\quad 0.605$ $\begin{array}{ll}\text { Chung 2011 A } & 0.609 \\ \text { Chung 2011 B } & 0.609\end{array}$ Cintra 2011 Cofta 2013 $\begin{array}{ll}\text { Cofta 2013 B } & 0.616 \\ \text { Cofta } 2013 \text { C } & 0.61\end{array}$ Czerniawska 2008 0.61 $\begin{array}{ll}\text { Davies 1994 } & 0.607 \\ \text { Drager 2010 } & 0.591\end{array}$ Garciario $2013 \mathrm{~A} \quad 0.611$ Garciario 2013 B $\quad 0.607$ $\begin{array}{ll}\text { Grassi } 2010 \text { A } & 0.574 \\ \text { Grassi } 2010 \text { B } & 0.600\end{array}$ Guasti 2011 Gambineri $2003 \quad 0.597$ Guill $2010 \mathrm{~A} \quad 0.584$ $\begin{array}{ll}\text { Guill } 2010 \text { B } & 0.583 \\ \text { IP } 2000 & 0.603\end{array}$ Kono $2007-0.625$ \begin{tabular}{ll} 
Kam 2006 & 0.604 \\
\hline & 0.587
\end{tabular} Lam $\begin{array}{ll}\text { Lavie } 2001 \text { B } & 0.608 \\ \text { Lavie } 2001 \text { C } & 0.611\end{array}$ Lefebvre $2008 \quad 0.593$ Lin $2013 \mathrm{~A}$ in $2013 \mathrm{~B}$ Luyster 2012 A $\quad 0.61$ Luyster 2012 B $\quad 0.608$ Luyster 2012 C $\quad 0.609$ \begin{tabular}{ll} 
Makino 2009 A & 0.608 \\
\hline & 0.614
\end{tabular} $\begin{array}{ll}\text { Makino } 2009 \mathrm{~B} & 0.603\end{array}$ $\begin{array}{ll}\text { Makino } 2009 \mathrm{~B} & 0.603 \\ \text { Makino } 2009 \mathrm{C} & 0.613\end{array}$ $\begin{array}{ll}\text { Matos } 2013 & 0.583\end{array}$ $\begin{array}{ll}\text { Matos } 2013 & 0.583 \\ \text { Minoguchi 2005 A } & 0.610\end{array}$ Minoguchi 2005 B $\quad 0.611$ Monneret $2010 \quad 0.601$ Monneret $2012 \quad 0.605$ $\begin{array}{ll}\text { Mcardle 2007 } & 0.605 \\ \text { Matr } & 0.600\end{array}$ Marin 2005 A $\quad 0.610$ Marin 2005 B $\quad 0.610$ Marin 2005 C $\quad 0.609$ Marin 2005 D $\quad 0.610$ Nazzaro 2008 A $\quad 0.608$
Nata Nazzaro 2008 B $\quad 0.610$ $\begin{array}{ll}\text { Pierola } 2007 & 0.608\end{array}$ Rusu 2012

Ryan 2007 0.604
0 Ryan 2007 C $\quad 0.604$ Roche $2009 \mathrm{~A} \quad 0.611$ Roche 2009 B $\quad 0.609$ $\begin{array}{ll}\text { Salord } 2009 & 0.599\end{array}$ Sharma 2006 A $\quad 0.610$ Sharma 2006 B $\quad 0.608$ Sahin 2011 A $\quad 0.586$ Sahin 2011 B $\quad 0.576$ Sahin 2011 C $\quad 0.572$ Sahin 2011 D $\quad 0.599$ Sahin 2011 E $\quad 0.590$ \begin{tabular}{ll} 
Sharabi 2003 & 0.584 \\
\hline & 0.609
\end{tabular}

Tan 2012 \begin{tabular}{ll} 
Togeiro 2013 B & 0.608 \\
\hline & 0.605
\end{tabular} Tokuda 2008 A $\quad 0.610$ Tokuda 2008 B $\quad 0.607$ $\begin{array}{lll}\text { Tsioufis } 2007 & 0.607\end{array}$ Utriainen 2013 A $\quad 0.607$ Utriainen $2013 \mathrm{~B} \quad 0.605$ Utriainen $2013 \mathrm{C} \quad 0.606$ Vatansever 2011 A 0.628 Vatansever 2011 B $\quad 0.613$ $\begin{array}{ll}\text { Varol 2010 A } & 0.609 \\ \text { Varol 2010 B } & 0.607\end{array}$ $\begin{array}{ll}\text { Varol 2010 B } & 0.607 \\ \text { Yeboah 2011 A } & 0.612\end{array}$ $\begin{array}{ll}\text { Yeboah 2011 A } & 0.612 \\ \text { Yeboah 2011 B } & 0.610\end{array}$ Wysocka 2013 A $\quad 0.612$ Wysocka 2013 B $\quad 0.629$ $\begin{array}{ll}\text { Zammaron 2008 A } & 0.604 \\ \text { Zammaron 2008 B } & 0.608\end{array}$

Statistics with study removed Lower Upper
limit
limit -Value p-Value $\begin{array}{cccccc}\text { error } & \text { Variance } & \text { i. } & & & \\ 0.084 & 0.007 & 0.420 & 0.748 & 6.971 & 0.000\end{array}$ $\begin{array}{llllll}0.088 & 0.008 & 0.429 & 0.746 & 6.872 & 0.000\end{array}$ $\begin{array}{llllll}0.088 & 0.008 & 0.433 & 0.779 & 6.863 & 0.000 \\ 0.081 & 0.007 & 0.399 & 0.715 & 6.903 & 0.000\end{array}$ $\begin{array}{llllll}0.088 & 0.008 & 0.422 & 0.768 & 6.753 & 0.000\end{array}$ $\begin{array}{llllll}0.089 & 0.008 & 0.436 & 0.784 & 6.867 & 0.000 \\ 0.088 & 0.008 & 0.432 & 0.778 & 6.855 & 0.000\end{array}$ $\begin{array}{llllll}0.089 & 0.008 & 0.434 & 0.781 & 6.863 & 0.000\end{array}$ $\begin{array}{llllll}0.088 & 0.008 & 0.440 & 0.786 & 6.950 & 0.000\end{array}$ $\begin{array}{llllll}0.088 & 0.008 & 0.435 & 0.781 & 6.887 & 0.000\end{array}$ $\begin{array}{llllll}0.087 & 0.008 & 0.406 & 0.746 & 6.637 & 0.000 \\ 0.088 & 0.008 & 0.422 & 0.767 & 6.748 & 0.000\end{array}$ $\begin{array}{llllll}0.089 & 0.008 & 0.433 & 0.780 & 6.854 & 0.000\end{array}$ $\begin{array}{llllll}0.088 & 0.008 & 0.433 & 0.780 & 6.869 & 0.000 \\ 0.088 & 0.008 & 0.431 & 0.777 & 6.838 & 0.000\end{array}$ $\begin{array}{llllll}0.088 & 0.008 & 0.438 & 0.784 & 6.924 & 0.000\end{array}$

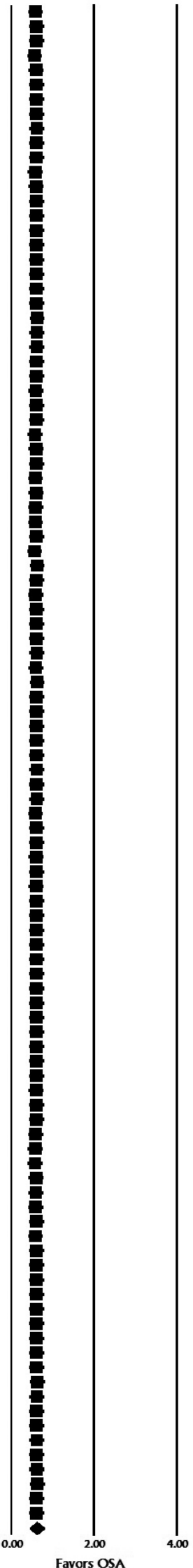

